\title{
Recent advances in materials and device technologies for aqueous hybrid supercapacitors
}

\author{
Qiuyue Gui ${ }^{1}$, Deliang Ba ${ }^{2}$, Linpo $\mathrm{Li}^{2}$, Wenyi $\mathrm{Liu}^{1}$, Yuanyuan $\mathrm{Li}^{{ }^{*}}$ and Jinping $\mathrm{Liu}^{1,3^{*}}$
}

\begin{abstract}
Aqueous hybrid supercapacitors (AHSCs) offer potential safety and eco-friendliness compared with conventional electrochemical energy storage devices that use toxic and flammable organic electrolytes. They can serve as the bridge between aqueous batteries and aqueous supercapacitors by combining the advantages of high energy of the battery electrode and high power as well as long lifespan of the capacitive electrode. Over the past few decades, extensive research efforts have been devoted to developing advanced materials and fascinating device architectures for AHSCs. However, further development related to the compatibilities between the battery-type electrode and capacitive electrode remains stagnant mainly due to discrepancy encountered in terms of reaction kinetics and capacity. This review focuses on the recent progress made in the field of AHSCs via elucidating the main concepts on the design of battery and capacitive electrodes and emerging electrolytes. In particular, ingenious AHSCs that possess either better flexibility toward materials selection or better device functionality such as those with "dual-ion" energy storage mechanism and non-polarity feature are also discussed. Recent advances and unresolved issues in multivalent ion hybrid devices (in particular, zinc-ion AHSCs) are further outlined. Finally, future research directions and challenges for AHSCs are presented, which are anticipated to deliver higher energy and demonstrate greater multifunctionalities for more breakthrough technology applications.
\end{abstract}

Keywords: aqueous hybrid supercapacitors, electrode materials, electrolytes, device technologies

\section{INTRODUCTION}

Achievement of secure and sustainable energy storage on large scale is one of the greatest scientific and societal challenges of this era. Electrical energy sources (EESs) as potential sustainable energy supplies play a vital role in our daily life because of the extensive use of various mobile electronic devices [1-3]. Electrochemical energy storage devices such as Li-ion batteries (LIBs) [4], Li-S batteries [5], $\mathrm{Li}^{-} \mathrm{O}_{2}$ batteries [6], and supercapacitors (SCs) [7-9] are high-efficiency EESs attracting tremendous interests in recent years, which have greatly reduced our dependence on fossil fuels [4,5]. Among them, LIBs have been widely used in portable electronics and are almost ready for emerging application in the field of electric/hybrid vehicles [4]. With their extended uses in different fields, the safety issues resulting from the use of flammable organic electrolytes and the growing cost of limited lithium sources have become more critical. Aqueous batteries using simple aqueous electrolytes are a fascinating alternative to solve the safety issue of organic electrolyte-based batteries [10]. To reduce the cost of LIBs, replacing lithium-based electrodes with sodium $(\mathrm{Na})$ - and potassium (K)-based ones and the constructions of $\mathrm{Na}$ - and $\mathrm{K}$ ion batteries have also emerged [11-15].

In specific application fields or cases that require energy storage devices with high power and extremely long lifespan, batteries are generally not qualified as they are difficult to be fully charged in short time and basically subjected to volume changes during each cycle. In contrast, SCs fulfill these requirements even though their energy density is inferior to that of batteries $[16,17]$. Since the discovery of electrical double layer capacitor (EDLC) by Helmholtz in 1879 [18], the charge storage process based on pure electrostatic charge accumulation at the electrode/ electrolyte interface and the electrode materials for EDLC have been extensively investigated. An alternative charge storage mechanism for SCs, that is pseudocapacitance via fast and reversible surface redox processes or redox reactions in quasitwo-dimensional (2D) planes in bulk crystal lattice, was proposed later. Since then, pseudocapacitive materials have been developed for tens of years [19-23]. Noteworthily, owing to the fast-charging ability and high power, SCs are typically employed as backup power sources to complement batteries. By using lowcost and nonflammable water-based electrolytes, SCs are also intrinsically safe, alike aqueous batteries [24]. Consequently, great research attempts have been made to develop aqueous SCs and related energy storage devices in the past few decades $[18,24,25]$.

As one of the key outcomes, aqueous hybrid SCs (AHSCs) that consist of one capacitive electrode and one battery-type electrode emerged at a historic moment by virtue of complementary advantages of batteries and capacitors (Fig. 1) [26-28]. By considering the charge storage mechanisms of two electrodes, the general working principles of AHSCs can be elucidated as follows [29,30]: during charging and discharging

\footnotetext{
${ }^{1}$ State Key Laboratory of Advanced Technology for Materials Synthesis and Processing, Wuhan University of Technology, Wuhan 430070, China

${ }^{2}$ School of Optical and Electronic Information, Huazhong University of Science and Technology, Wuhan 430074, China

${ }^{3}$ State Center for International Cooperation on Designer Low-carbon \& Environmental Materials, School of Materials Science and Engineering, Zhengzhou University, Zhengzhou 450001, China

* Corresponding authors (emails: liyynano@hust.edu.cn (Li Y); liujp@whut.edu.cn (Liu J))
} 


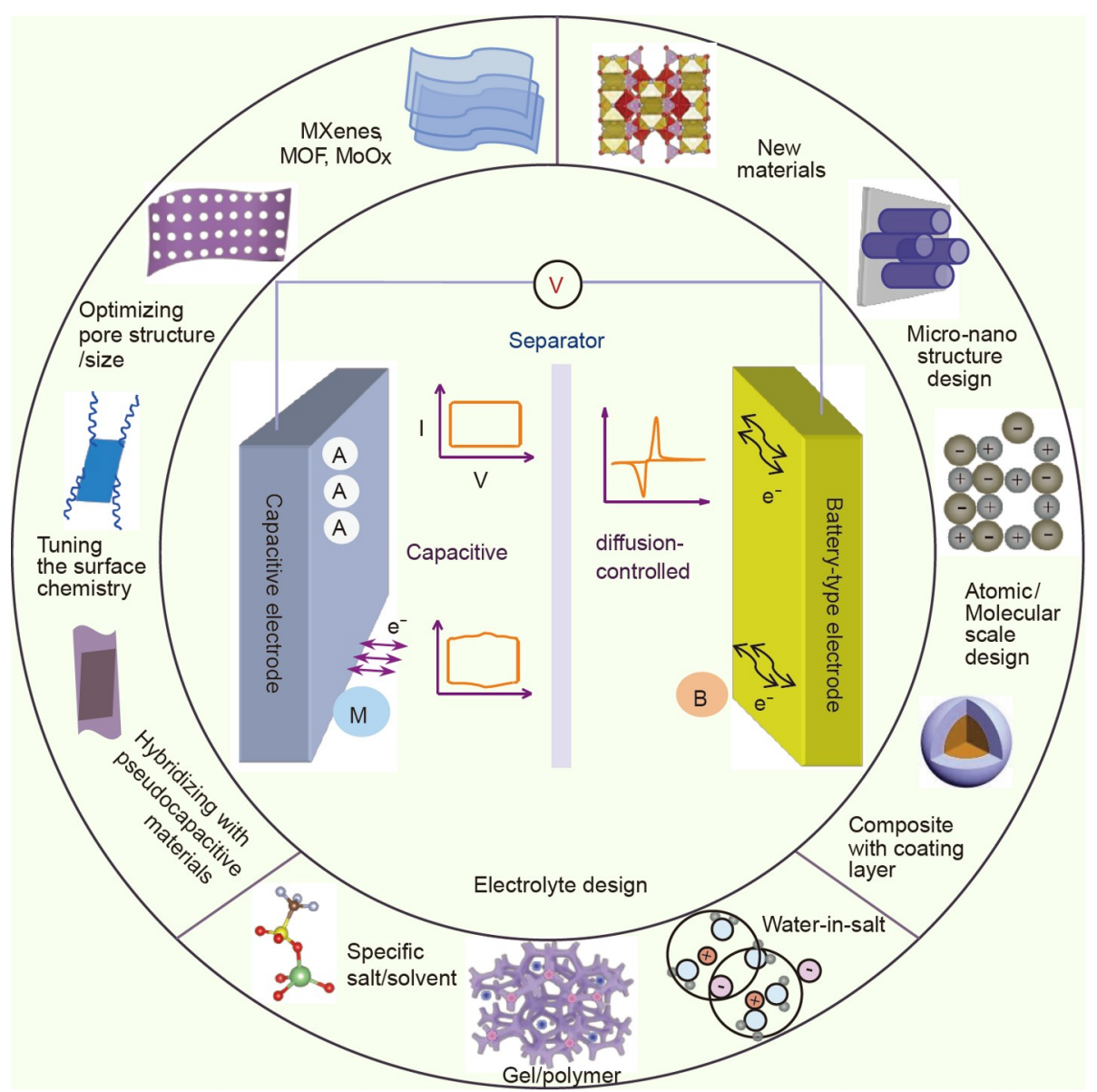

Figure 1 Illustration of the device structure, charge storage mechanism, materials design concepts of AHSCs. "A (M)" and "B" are ions involved in charge storage process for capacitive electrode and battery-type electrode, respectively.

process, ions in electrolytes move to electrodes. The capacitive electrode typically undergoes reversible adsorption/desorption of ion (A) at the electrode/electrolyte interface or rapid surface/ near-surface Faradaic reaction $(\mathrm{M})$ to store charges; however, the other battery-type electrode suffers bulk redox reactions (B ion involved) with charge transfer across the electrode/electrolyte interface. According to the above-stated fundamentals, the capacitive electrode with fast electrochemical kinetics can offer rapid energy uptake and delivery. Further, the battery-type electrode with intensive redox activity can provide more energy, thus ideally endowing AHSCs with both high power and energy density. In particular, the asymmetric device configuration with different charge storage mechanisms of electrodes can increase the hydrogen and oxygen evolution overpotentials in aqueous electrolytes. As a result, the device voltage thereby extends beyond $1.5 \mathrm{~V}$ and even up to $\sim 2.0 \mathrm{~V}$ (intrinsic electrochemical stability window of water is merely $\sim 1.23 \mathrm{~V}$ ) $[14,31]$. Therefore, AHSCs are expected to deliver larger amount of energy than conventional aqueous SCs and superior power performance to aqueous batteries. Successful examples were demonstrated using a Faradaic conversion positive electrode $\left(\mathrm{PbO}_{2} / \mathrm{PbSO}_{4}\right.$ in aqueous $\mathrm{H}_{2} \mathrm{SO}_{4}$ or $\mathrm{NiOOH} / \mathrm{Ni}(\mathrm{OH})_{2}$ in aqueous $\left.\mathrm{KOH}\right)$ and a capacitive activated carbon (AC) negative electrode [32]. In recent years, various other types of aqueous AHSCs such as aqueous $\mathrm{Li} / \mathrm{Na} / \mathrm{K}$-ion capacitors (ALICs, ASICs, and APICs, respectively) and redox AHSCs have been proposed and devel- oped. Moreover, a wide spectrum of new electrode materials have been utilized to achieve innovative electrode couples [11,14,33-36]. Unfortunately, to boost the performance on device level and widen the application fields of AHSCs, critical challenges are still encountered in understanding the energy storage mechanism of new hybrid systems, engineering the surface chemistry/structure/morphology of electrode materials, regulating the electrolytes, and designing stable interfaces within the device.

By using anode and cathode with different energy storage mechanisms, it generally becomes more difficult to realize perfect charge and kinetics balance between the two electrodes in AHSCs. First, the intercalation/deintercalation or conversion kinetics in battery-type electrode cannot match well with the capacitive electrode, which deteriorates the practical rate capacity and cycling stability of the hybrid devices [37-39]. Thus, strategies to deal with this issue lie in developing advanced battery-type electrodes with specific components, micro-nanostructures, or electronic and crystal structures to promote the charge transfer at the interfaces and electron/ion transport in the solid electrodes [40-43]. The unsatisfactory specific capacitance of the capacitive electrodes is another factor that limits the practical performance of AHSCs; this is attributed to the fact that the capacitive electrode should generally be much thicker and heavier than battery electrode to achieve the charge balance, which is inconvenient for device assembly and not beneficial to 
volumetric/gravimetric performance. The increased weight and volume may also lead to limited electrolyte/electrode interfacial contact that can restrict the materials utilization and rate performance. Therefore, to address this issue, the major challenge is to boost the specific capacitance of the capacitive electrodes. Notably, this can be achieved by optimizing the pore structure/ size, tuning the surface chemistry, and doping of EDLC materials (capable of introducing pseudocapacitive effect), or by directly using high-capacity pseudocapacitive materials [44-47]. The difference in cycling stability between battery-type electrode and capacitive electrode is also a key to design high-performance AHSCs. In addition to the matching consideration of positive and negative electrodes, the energy density of AHSCs has been of another concern in the SC field. Owing to water electrolysis involving $\mathrm{H}_{2}$ and $\mathrm{O}_{2}$ evolution, the voltage window of AHSCs is generally limited to $2.0 \mathrm{~V}$ despite its asymmetric configuration [48]. Thus, according to the equation $E=1 / 2 C V^{2}$ (where $C$ and $V$ are the specific capacitance and operating voltage of the device, respectively), the energy density of AHSCs is much lower than that of conventional SCs. Fortunately, recent advances have indicated that the $V$ can be significantly widened via designing advanced electrolyte, electrode, and robust electrode/electrode interface [49]. To efficiently power flexible and wearable electronics, afford miniaturized energy delivery or harvest with high power capabilities for Internet of Things, significant research efforts have also been devoted to developing thin-film flexible AHSCs using quasi-solid-state/gel electrolytes and flexible/ bendable current collectors [50-52]. Such functionality design into device was also combined with electrode engineering to construct new types of AHSCs, which demonstrates promising potential in some specific application scenarios $[7,51,53]$. Despite the existence of some related reviews and perspectives $[7,16,18,19,22,25,26]$, advances on new concepts of designing electrode, electrolyte, and device of AHSCs have not been well outlined.

In this review, an attempt was made to briefly summarize the key performance improvement strategies for AHSCs in terms of the design of advanced battery-type and capacitive electrodes and the optimization of electrolyte (e.g., concentration regulation and hydrogel electrolyte design). The ingenious design of some emerging AHSC devices, such as "dual-ion" AHSC and non-polarity AHSC are also expatiated, which are assembled with novel device structure and operated based on interesting charge storage process. Furthermore, recent advances and unresolved issues in multivalent ion hybrid devices, in particular, in the most popular zinc-ion AHSCs are discussed herein. Finally, perspectives on the challenges and opportunities for developing future AHSCs are presented with the objective of maximizing the amount of stored energy and the speed of energy delivery as well as enriching the device multifunctionalities.

\section{DESIGN OF BATTERY-TYPE ELECTRODES IN AHSCs}

As one of the key components in AHSCs, the battery-type electrode has been focused upon in recent decades for the sake of alleviating the kinetics discrepancy between the electrode and capacitive counterpart to improve the cycling performance and increase the energy density of device at high power. Till date, several approaches have been developed to realize the abovementioned objectives via promoting the electron transport and ion diffusion within solid electrode and accelerating the charge transfer at the interface. These approaches are as follows: (1) micro-nanostructures manipulation, such as growth of ordered arrayed electrode architecture and sophisticated coating of pristine materials with stabilizing layer, conductive layer, or energy-contributing species; (2) electronic and crystal structures tuning (solid-solution design, intrinsic defects, doping, etc.); and (3) searching for new battery-type materials with rapid electrochemical kinetics for AHSCs (Fig. 1, right side).

\section{$\mathrm{Li}^{+} / \mathrm{Na}^{+} / \mathrm{K}^{+}$storage electrodes}

Similar to the use in non-AH devices, $\mathrm{Li}^{+} / \mathrm{Na}^{+} / \mathrm{K}^{+}$storage materials such as intercalation/insertion compounds have also attracted significant research interest as battery-type electrode materials for AHSCs. Considering the standard redox potentials of alkali ion storage in these materials $\left(3.3-4.5 \mathrm{~V}\right.$ versus $\mathrm{Li}^{+} / \mathrm{Li}$; ca. $0-1.2 \mathrm{~V}$ versus $\mathrm{Ag} / \mathrm{AgCl}$ ) and overpotentials during practical reactions, actually quite a few cathodes in non-aqueous systems can be utilized directly in AHSCs without the interference from apparent oxygen evolution reaction. These cathode materials include $\mathrm{Mn}$-based oxides (e.g., $\mathrm{LiMn}_{2} \mathrm{O}_{4}$ [54], $\mathrm{Ni}_{0.25} \mathrm{Mn}_{0.75} \mathrm{O}$ [55], $\mathrm{Na}_{4} \mathrm{Mn}_{9} \mathrm{O}_{18}$ [56], and $\left.\mathrm{K}_{x} \mathrm{MnO}_{2}[57,58]\right)$, polyanionic compounds (e.g., $\mathrm{LiFePO}_{4}$ [59] and $\mathrm{Na}_{2} \mathrm{VTi}\left(\mathrm{PO}_{4}\right)_{3}$ [60]), Prussian blue analogs (PBAs) (e.g., $\mathrm{Na}_{2} \mathrm{NiFe}(\mathrm{CN})_{6}$ [61] and $\mathrm{K}_{x} \mathrm{Fe}_{y} \mathrm{Mn}_{1-y}[\mathrm{Fe}-$ $\left.(\mathrm{CN})_{6}\right]_{w} \cdot z \mathrm{H}_{2} \mathrm{O}$ [62]), and other layered compounds (e.g., $\mathrm{Na}_{2 / 3} \mathrm{Ni}_{1 / 4} \mathrm{Mn}_{3 / 4} \mathrm{O}_{2}$ [63] and $\mathrm{LiCoO}_{2}$ [64]). In contrast, many anode materials used for non-AH devices have much lower redox potentials beyond hydrogen evolution and are impossible to be employed in AHSCs. Therefore, relatively few anode materials, such as Ti-based polyanionic compounds $\left(\mathrm{LiTi}_{2}\left(\mathrm{PO}_{4}\right)_{3}\right.$ [65] and $\left.\mathrm{NaTi}_{2}\left(\mathrm{PO}_{4}\right)_{3}[66]\right)$, carbonyl-based organic compounds (poly-(naphthalene-4-formyl ethylenediamine [67]), and vanadium-based oxides $\left(\mathrm{V}_{2} \mathrm{O}_{5}\right.$ [68] and $\mathrm{Na}_{2} \mathrm{~V}_{6} \mathrm{O}_{16} \cdot n \mathrm{H}_{2} \mathrm{O}$ [69]) are available. Several comprehensive reviews have discussed the cathode and anode materials for $\mathrm{Li}^{+} / \mathrm{Na}^{+}$AHSCs $[14,26,27,70,71]$. Although morphological characterization and micro/nano-structure engineering have been widely investigated toward battery-type electrodes for boosting the redox kinetics and cycling stability, other promising strategies such as electronic structure tuning via doping or formation of solid solution have also been proposed and developed in recent years $[55,66,72,73]$.

A good example was demonstrated by fabricating Ni-Mn-O solid-solution cathode for ALICs [55]. With similar radius to 3dmetal elements and the same $\mathrm{NaCl}$ crystal structure to $3 \mathrm{~d}$-metal monoxides, $\mathrm{MnO}$ easily forms solid solutions with the introduction of other metal ions such as $\mathrm{Ni}^{2+}$ [74]. In the study, a unique $\mathrm{MnO}$-based 3d-metal monoxide solid-solution cathode $\left(\mathrm{Ni}_{0.25} \mathrm{Mn}_{0.75} \mathrm{O}\right)$ was synthesized directly on current collector substrate with a nanoprism array architecture (Fig. 2a). The synthesis process involved the direct hydrothermal growth of $\mathrm{Ni}-\mathrm{Mn}$ carbonate nanoprisms and subsequent thermal decomposition into solid-solution oxide during annealing. Inset of Fig. $2 \mathrm{~b}$ illustrates that the $\mathrm{Ni}_{0.25} \mathrm{Mn}_{0.75} \mathrm{O}$ electrode exhibits two pairs of redox peaks with both higher current densities and lower polarizations compared with the pristine $\mathrm{MnO}$ electrode in the cyclic voltammogram (CV) curves. In-depth electrochemical impedance spectroscopy (EIS) studies reveal that $\mathrm{Ni}$ incorporation not only decreases the Ohmic resistance $\left(R_{\mathrm{s}}\right)$ and charge transfer resistance $\left(R_{\mathrm{ct}}\right)$, but also enhances the $\mathrm{Li}^{+}$diffusion coefficient in the cathode. Moreover, in general, the $\mathrm{Ni}_{0.25} \mathrm{Mn}_{0.75} \mathrm{O}$ electrode demonstrates diffusion coefficient to be 

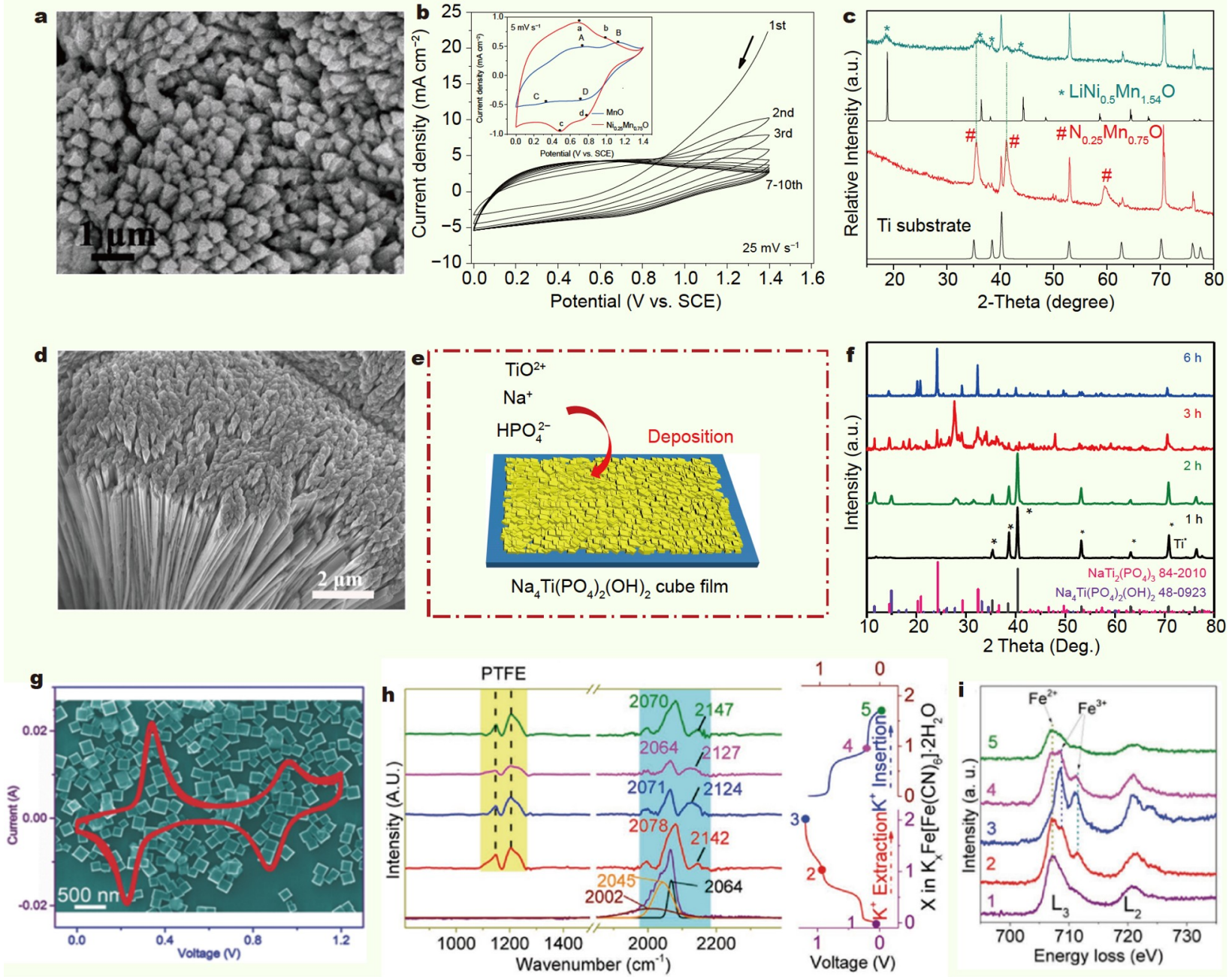

Figure $2(\mathrm{a}, \mathrm{b})$ Top-view scanning electron microscope (SEM) and the CV activation process of the $\mathrm{Ni}_{0.25} \mathrm{Mn}_{0.75} \mathrm{O} @ \mathrm{C}$ electrode. (c) XRD patterns of the $\mathrm{Ni}_{0.25} \mathrm{Mn}_{0.75} \mathrm{O} @ \mathrm{C}$ electrode before and after activation. Reprinted with permission from Ref. [55], Copyright 2017, Wiley. (d) SEM image of NaTi ${ }_{2}\left(\mathrm{PO}_{4}\right)_{3}$. (e) Schematic illustration of the interfacial deposition process of $\mathrm{Na}_{4} \mathrm{Ti}\left(\mathrm{PO}_{4}\right)_{2}(\mathrm{OH})_{2}$. (f) XRD of the products prepared in $4 \mathrm{~mol} \mathrm{~L}^{-1} \mathrm{NaTi}_{2}\left(\mathrm{PO}_{4}\right)_{3}$ with $1,2,3$, and $6 \mathrm{~h}$ of reaction. Reprinted with permission from Ref. [75], Copyright 2021, Wiley. (g-i) SEM image, CV, ex situ FTIR and EELS spectra of the $\mathrm{K}_{2} \mathrm{Fe}^{\mathrm{II}}\left[\mathrm{Fe}^{\mathrm{II}}\right.$ $\left.(\mathrm{CN})_{6}\right] \cdot 2 \mathrm{H}_{2} \mathrm{O}$ electrode. Reprinted with permission from Ref. [78], Copyright 2017, Wiley.

2.68 times that of pure $\mathrm{MnO}$ electrode. The promoted electron transport and ion diffusion ultimately result in much better rate performance of the $\mathrm{Ni}_{0.25} \mathrm{Mn}_{0.75} \mathrm{O}$ cathode, facilitating its pairing with AC anode. Interestingly, the solid-solution cathode is able to store energy within a wide potential range of $0-1.4 \mathrm{~V}$ versus saturated calomel electrode enabled by a simple but unique $\mathrm{CV}$ activation. After ca. 10 times of $\mathrm{CV}$ cycling, the $\mathrm{Ni}_{0.25} \mathrm{Mn}_{0.75} \mathrm{O}$ cathode almost suppresses the oxygen evolution in the high potential range (Fig. 2b). Fig. 2c exhibits the X-ray diffraction (XRD) result, which evidences the novel phase transformation of $\mathrm{Ni}_{0.25} \mathrm{Mn}_{0.75} \mathrm{O}$ before and after the activation from highly crystalline $\mathrm{Ni}_{0.25} \mathrm{Mn}_{0.75} \mathrm{O}$ to poorly crystallized $\mathrm{LiNi}_{0.5} \mathrm{Mn}_{1.5} \mathrm{O}_{4}$, which is believed to dominantly utilize transferred electrons (competing with water). Consequently, the assembled ALIC worked well within a ultrahigh voltage window of $2.4 \mathrm{~V}$, delivering the maximum volumetric energy density of $4.72 \mathrm{~mW} \mathrm{~h} \mathrm{~cm}^{-3}$ and power density of $776 \mathrm{~mW} \mathrm{~cm}^{-3}$. ASICs were also assembled using high-quality $\mathrm{NaTi}_{2}\left(\mathrm{PO}_{4}\right)_{3}$ and $\mathrm{N}$-doped carbon. The porous single-crystal $\mathrm{NaTi}_{2}\left(\mathrm{PO}_{4}\right)_{3}$ with uniform size was fabricated via a novel liquid transformation of ultrathin $\mathrm{TiO}_{2}$ nanosheets and subsequently coated with a conductive carbon sheath [66]. $\mathrm{NaTi}_{2}\left(\mathrm{PO}_{4}\right)_{3} @ \mathrm{C}$ exhibits high capacities of $80-102 \mathrm{~mA} \mathrm{~h}^{-1}$ at varied current densities of $0.5-3 \mathrm{Ag}^{-1}$, benefitting from the synergistic effect of efficient ion diffusion enabled by the porous network and improved electronic conductivity and structural stability provided by the coated carbon shell. Consequently, the ASICs achieve a high first discharge capacity of $89 \mathrm{~mA} \mathrm{~h} \mathrm{~g}^{-1}$ at $0.5 \mathrm{Ag}^{-1}$, and the high value of the capacity remains $\left(63 \mathrm{~mA} \mathrm{~h} \mathrm{~g}^{-1}\right)$ even after 400 cycles.

$\mathrm{NaTi}_{2}\left(\mathrm{PO}_{4}\right)_{3}$ with a nanowire array structure was also specifically designed to enable the construction of high-performance ASICs [75]. $\mathrm{NaTi}_{2}\left(\mathrm{PO}_{4}\right)_{3}$ nanowires were grown on thin titanium foil (Fig. 2d) by elaborately utilizing the weak ionization chemistry of $\mathrm{NaH}_{2} \mathrm{PO}_{4}$ (NHP), where single-agent NHP not only aided in partial etching of titanium to release $\mathrm{TiO}^{2+}$, but also induced the interfacial phase transformation of pre-deposited orthomorphic $\mathrm{Na}_{4} \mathrm{Ti}\left(\mathrm{PO}_{4}\right)_{2}(\mathrm{OH})_{2}$ cubes (Fig. 2e) to hexagonal $\mathrm{NaTi}_{2}\left(\mathrm{PO}_{4}\right)_{3}$. XRD patterns of the products at different growth stages unambiguously revealed the importance of weak dissociation chemistry of NHP, interfacial deposition, and phase 
transformation (Fig. 2f). Benefiting from the hierarchical architecture to facilitate charge and mass transport, the $\mathrm{NaTi}_{2}\left(\mathrm{PO}_{4}\right)_{3}$ could stably be operated at significantly high rates of $15-150 \mathrm{C}$ with high capacities. Furthermore, the resulting hydrogel ASIC delivered the maximum volumetric energy density of $\sim 5.8 \mathrm{~mW} \mathrm{~h} \mathrm{~cm}^{-3}\left(1.0 \mathrm{mg} \mathrm{cm}^{-2} \mathrm{NaTi}_{2}\left(\mathrm{PO}_{4}\right)_{3}\right)$. When the $\mathrm{NaTi}_{2}\left(\mathrm{PO}_{4}\right)_{3}$ mass loading was increased to $3.5 \mathrm{mg} \mathrm{cm}^{-2}$, the ASIC still achieved high energy density and power density comparable to commercial solid-state thin-film batteries such as Enfilm 700 and Stereax M250.

Compared with the advanced design of $\mathrm{Li}^{+} / \mathrm{Na}^{+}$storage electrodes, the design of $\mathrm{K}^{+}$storage electrodes for AHSCs is still at the early stage and needs substantial advancement. The driving forces for developing $\mathrm{K}^{+}$storage devices are the low cost and abundance $(2.09 \mathrm{wt} \%$ in the earth's crust) of potassium resources, and the similar physical and chemical properties of $\mathrm{K}^{+}$to $\mathrm{Li}^{+}$ and $\mathrm{Na}^{+}$[62]. However, owing to the large-sized $\mathrm{K}^{+}$ion $(1.38 \AA$ ) $\left(r_{\mathrm{Li}^{+}}=0.76 \AA, r_{\mathrm{Na}^{+}}=1.02 \AA\right)$ and strong $\mathrm{K}^{+}-\mathrm{K}^{+}$electrostatic repulsion, the intercalation/insertion of $\mathrm{K}^{+}$into crystal lattice of electrode materials is generally more difficult and even it is not easy to stabilize the intercalated/inserted electrode structure. This issue becomes more serious in aqueous electrolytes due to the strong solvation of $\mathrm{K}^{+}$by water and the easy dissolution of $\mathrm{K}^{+}$-incorporated electrode materials into solution. Consequently, many $\mathrm{K}^{+}$storage electrodes exhibit poor cyclability, low capacity, and inferior rate capability in aqueous electrolytes [11]. A strategy to overcome this limitation includes the selection of a new class of electrode materials, for example, PBAs with openframework structure, which can be easily fabricated by a lowtemperature solvothermal process [76,77]. Fig. 2d demonstrates that $\mathrm{K}_{2} \mathrm{Fe}^{\mathrm{II}}\left[\mathrm{Fe}^{\mathrm{II}}(\mathrm{CN})_{6}\right] \cdot 2 \mathrm{H}_{2} \mathrm{O}$ nanocubes with a uniform size distribution can be successfully attained, and they have the perovskite-type structure that can form a $3 \mathrm{D}$ channel for fast transport of metal ions without collapse of the crystal framework [78]. As expected, two pairs of well-separated redox peaks are observed at $0.96 / 0.88 \mathrm{~V}$ and $0.34 / 0.23 \mathrm{~V}$ in $\mathrm{CV}$ profiles, indicating two-electrons (per formula unit) transfer and exceptionally high capacities. In order to confirm the structural evolution and charge storage mechanism of $\mathrm{K}_{2} \mathrm{Fe}^{\mathrm{II}}\left[\mathrm{Fe}^{\mathrm{II}}(\mathrm{CN})_{6}\right] \cdot 2 \mathrm{H}_{2} \mathrm{O}$ cathode during the electrochemical process, ex situ Fourier transform infrared (FTIR) spectroscopy measurements and ex situ electron energy loss spectroscopy (EELS) were carried out to record the transformation of the crystal structure (Fig. 2e, f). It was found that the cathode underwent reversible structural evolution upon $\mathrm{K}^{+}$intercalation/deintercalation associated with the redox reaction between $\mathrm{Fe}^{\mathrm{III}}$ and $\mathrm{Fe}^{\mathrm{II}}$ benefiting from the intrinsic feature of large open-framework structure of $\mathrm{K}^{+}$, and the $\mathrm{K}_{2} \mathrm{Fe}^{\mathrm{II}}\left[\mathrm{Fe}^{\mathrm{II}}(\mathrm{CN})_{6}\right] \cdot 2 \mathrm{H}_{2} \mathrm{O}$ cathode demonstrated good rate performance and cycling stability ( $>500$ cycles at $21.4 \mathrm{C}$ ). Based on the above mentioned consideration, selection of materials with large open crystal frameworks or channels as the batterytype electrodes of APICs is particularly promising and deserves more in-depth systematic explorations in near future.

Noteworthily, only limited studies on APICs have been carried out till date due to the significant lack in qualified aqueous $\mathrm{K}^{+}$ storage battery-type materials. Fortunately, techniques applied to aqueous $\mathrm{Li}^{+}$and $\mathrm{Na}^{+}$electrode materials for improving the rate, cycling, and energy, in principle, can be utilized for $\mathrm{K}^{+}$storage as well. With this in mind, several possible categories of battery electrode materials such as titanium- and manganese-based oxides, polyanion-type compounds, and other PBAs can be envisaged in the near future for developing advanced APICs.

\section{Battery electrodes for alkaline AHSCs}

Compared with $\mathrm{Li}^{+} / \mathrm{Na}^{+} / \mathrm{K}^{+}$intercalation/insertion electrodes in neutral electrolytes, charge storage electrodes in alkaline electrolytes, such as transition metal oxides, hydroxides, and even sulfides, nitrides, and phosphides, in general, offer larger theoretical specific capacity due to their intensive redox activities (when reacting with $\mathrm{OH}^{-}$, accompanied by the valence changes of transition metal ions) $[41,71,73,79-84]$. The main drawback is that most of these materials are not well conductive, offering limited electron transport ability. This limitation prevents them from fully engaging in the electrochemical reactions in the alkaline electrolytes, in particular, at high rates. In order to boost the redox reactions within a wide rate range, enhancement in the electronic conductivity while maintaining fast ion diffusion in the solid electrodes is highly desirable. One promising approach involves the design of mesoporous (but continuous) and ordered $3 \mathrm{D}$ electrode architecture $[34,85,86]$. For instance, our group once developed an integrated mesoporous copper-nickel oxide $((\mathrm{Cu}, \mathrm{Ni}) \mathrm{O})$ nanowire array, consisting of $\mathrm{CuO}$ and $\mathrm{NiO}$ uniformly fused into nanowires and offering synergistic effects (Fig. 3a, b) [87]. The interconnected $\mathrm{NiO}$ and $\mathrm{CuO}$ nanoparticles resulted in the generation of numerous mesopores with a size of $\sim 4 \mathrm{~nm}$, facilitating the electrolyte penetration and shortening the ion diffusion length. Notably, the integration of $\mathrm{CuO}$ was found to improve the electronic conductivity of the hybrid electrode. In particular, the molar ratio of $\mathrm{Ni}$ to $\mathrm{Cu}$ in the nanowires could be readily tuned, thus making the capacity of the electrode highly controllable (Fig. 3c). This helped to optimize the nanowire array cathode and facilitated the flexible charge balance with the $\mathrm{AC}$ anode to construct a high-performance device. Consequently, the assembled AHSCs of $(\mathrm{Cu}, \mathrm{Ni}) \mathrm{O}_{(+)} / / \mathrm{AC}_{(-)}$displayed superior rate capability and high power density $\left(5213.4 \mathrm{~W} \mathrm{~kg}^{-1}\right)$.

Besides architectural design, element doping (with nonmetal, metal, or multi-elements) $[84,88,89]$, coating with conducting carbons or polymers (e.g., polypyrrole (PPy) and polyaniline (PANI) $[44,71]$, surface functionalization and surface activation $[90,91]$, etc. have also been utilized to improve the electron transport ability and electroactive sites of transition metal compounds electrode. Yang et al. [84] demonstrated a good example by fabricating edge site-enriched nickel-cobalt sulfide nanoparticles on graphene (Ni-Co-S/G; Fig. 3d) to form integrated hybrid architectures via an in situ chemically converted method. The introduction of graphene significantly enhanced the electronic conductivity of the hybrid electrode, and density functional theory (DFT) calculations showed that the Ni-Co-S edges consisted of abundant electroactive sites and strong affinity to $\mathrm{OH}^{-}$in the electrolyte (Fig. 3e). As a result, an enhanced electrochemical activity was attained, which was further proved by EIS, as shown in Fig. 3f. Benefiting from the strong binding to graphene and the rich redox reaction sites presented at the edges of nanoparticles, an alkaline AHSC device using Ni-Co-S/G hybrids as positive electrode and $2 \mathrm{D}$ porous carbon nanosheets (PCNS) as negative electrode delivered a specific capacity of $\sim 122 \mathrm{Fg}^{-1}$ at a high current density of $1 \mathrm{~A} \mathrm{~g}^{-1}$, which was still $105 \mathrm{Fg}^{-1}$ at $10 \mathrm{Ag}^{-1}$ with $86 \%$ of capacity retention rate.

In recent years, extensive studies have been attempted on alkaline AHSCs using various transition metal oxides/sulfides/ phosphides with diverse morphologies as cathode materials. In particular, metal sulfides and phosphides with better con- 

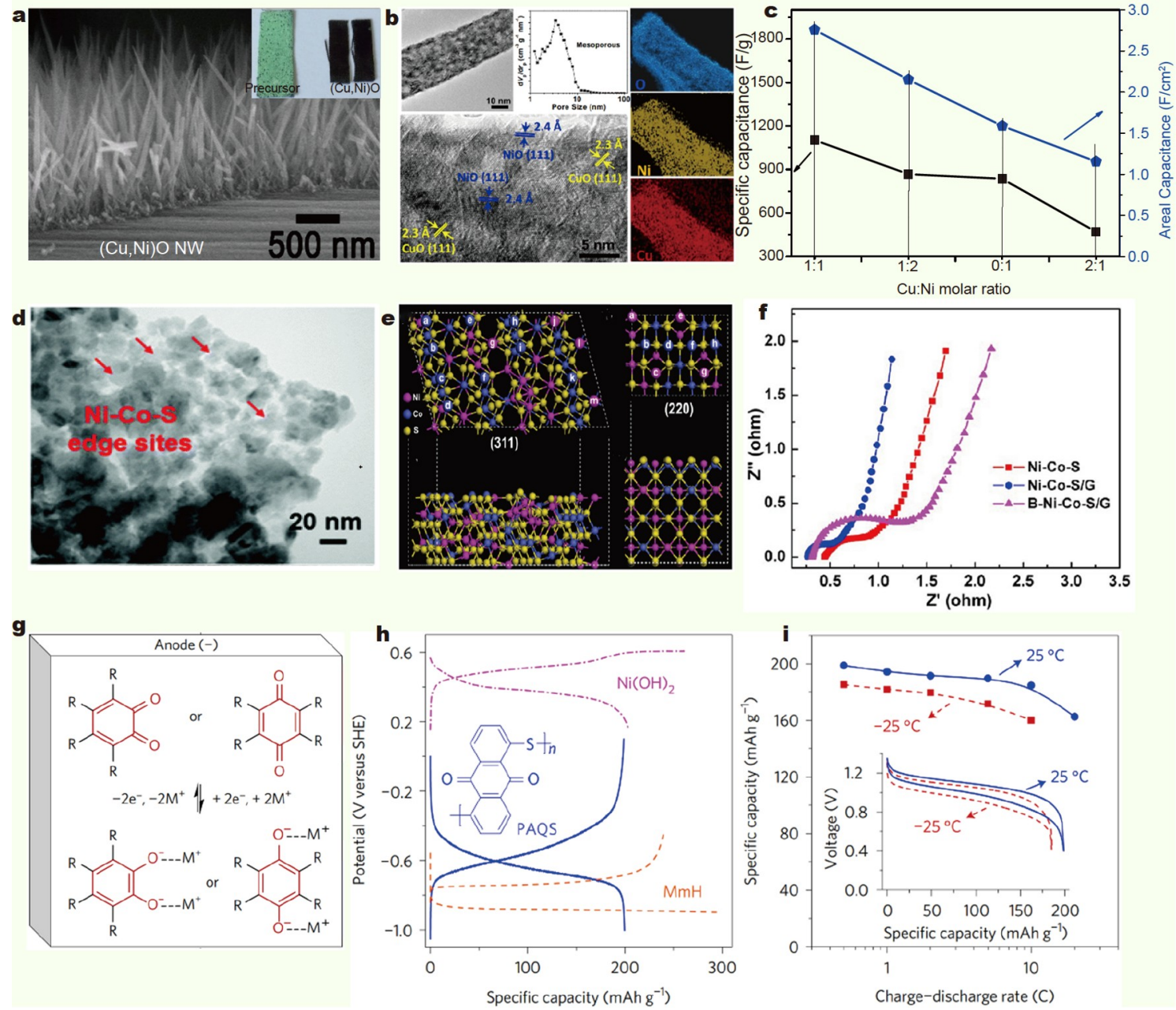

Figure 3 (a, b) SEM and transmission electron microscopy (TEM) images of $(\mathrm{Cu}, \mathrm{Ni}) \mathrm{O}$ nanowires. (c) The capacity of nanowires with different Cu:Ni molar ratios. Reprinted with permission from Ref. [87], Copyright 2016, Royal Society of Chemistry. (d-f) TEM images, structural models and EIS of the Ni-Co-S/G hybrids. Reprinted with permission from Ref. [84], Copyright 2016, Royal Society of Chemistry. (g) The anode side shown by the redox/ion-coordination reaction of 1,2-benzoquinone (left) and 1,4-benzoquinone (right) structures. (h) Galvanostatic charge-discharge profiles of PAQS and $\mathrm{Ni}(\mathrm{OH})_{2}$. (i) Capacity of a $\mathrm{Ni}(\mathrm{OH})_{2} / / \mathrm{PAQS}$ cell charged/discharged at $25 /-25^{\circ} \mathrm{C}$. Reprinted with permission from Ref. [99], Copyright 2017, Nature Publishing Group.

ductivity were generally considered than their oxide counterparts [92-94], thus attracting progressively more attention. Nevertheless, continuous charging and discharging in basic electrolyte is likely to result in the formation of transition metal hydroxide as a passivation layer on the electrode surface of metal sulfides and phosphides, which to some extent hinders the subsequent ion diffusion and deteriorates the reaction kinetics $[92,95]$. As of now, clear and systematic understanding of the fundamentals during this process has not been comprehensively attained. In future research, it is thus quite necessary to explore the underlying charge storage mechanism and principles, and in particular, novel solutions to address the surface evolution issue. Thus, stable, fast-charging, and high-capacity cathodes of metal sulfides and phosphides are highly desirable.

Furthermore, organic materials have also been attracting great interests in aqueous energy storage devices in the past few years $[96,97]$. One class of such materials is quinones with excellent chemical stability. Their reduction potentials can be readily tuned from 1.7 to $3.2 \mathrm{~V}$ versus $\mathrm{Li}^{+} / \mathrm{Li}$ upon molecular engineering [98]. In the early period, quinones were mainly considered for nonaqueous metal-ion batteries and aqueous flow batteries, and their use in other aqueous batteries was quite rare. Despite this, quinones as stable aqueous anode materials have been systematically investigated recently based on a redox/ioncoordination reaction mechanism. For example, 1,2-benzoquinone (left) and 1,4-benzoquinone (right) were reported to store charges efficiently in alkaline/acidic/neutral electrolytes (Fig. 3g) [99]. Poly(anthraquinonyl sulfide) (PAQS) was able to charge and discharge at $\sim-0.6 \mathrm{~V}$ versus standard hydrogen electrode (SHE) with a specific capacity of $\sim 200 \mathrm{mAh} \mathrm{g}^{-1}$ and low potential polarization (Fig. 3h). The assembled $\mathrm{Ni}(\mathrm{OH})_{2} / / \mathrm{PAQS}$ device delivered $100 \%$ depth of discharge for 1350 cycles at $1 \mathrm{C}$ $\left(200 \mathrm{~mA} \mathrm{~g}^{-1}\right)$ with $88 \%$ capacity retention. It also exhibited excellent rate performance up to $10 \mathrm{C}$ and could work well in a wide temperature range from 25 to $-25^{\circ} \mathrm{C}$, as displayed in Fig. $3 \mathrm{i}$. The above-mentioned results indicate the great application potential of quinones as anodes in AHSCs.

Transition metal oxides are another type of anode materials for alkaline AHSCs. Among them, iron oxides are promising due to their high theoretical capacity resulting from an aqueous conversion reaction $[100,101]$. However, the theoretical value can only be realized upon complete conversion $\left(\mathrm{Fe}^{3+} \rightleftharpoons \mathrm{Fe}^{0}\right)$ 
within a wide negative potential window (extended to ca. $-1.3 \mathrm{~V}$ vs. $\mathrm{Ag} / \mathrm{AgCl})$. As a result, a relatively huge volume change and inevitable water electrolysis (hydrogen evolution) occur during the charge storage process, which eventually leads to drastic decay in capacity and electrode failure after merely tens to a hundred of cycles $[102,103]$. The rate performance of iron oxide anodes in alkaline electrolyte was also affected by the formation of iron hydroxide passivation layer. To address the abovementioned problems, our group has made continuous efforts to modify the surface of iron oxides with carbon or oxide layer, for the purpose of restricting the variation in inner volume, which can enhance the electronic conductivity or alleviate hydrogen evolution [104-106]. In detail, a "carbon shell protection" solution and an interesting "carbon glue" penetration strategy (Fig. 4a) toward $\mathrm{Fe}_{3} \mathrm{O}_{4}$ nanorod film anode [104,105], were, respectively, proposed by our research group. The carbon protection method not only buffered the inner volume expansion of iron oxide and maintained the cycling stability, but also improved the conductivity of anode film, which in combination with the merits of ordered array architecture (i.e., the direct electron transport pathway), enabled good rate capability (Fig. 4b). However, noteworthily, the attractive cycling stability (after 1000 cycles and 99\% capacity retention) could only be obtained at suitable carbonization temperature, as shown in Fig. 4c. Another efficient solution we proposed is the conformal surface coating of amorphous $\mathrm{TiO}_{2}$ toward iron oxide via atomic layer deposition (ALD) [106]. The coating thickness was quite uniform and could be readily tuned by controlling the deposition time. Optimal shell thickness was found to be $\sim 10 \mathrm{~nm}$ (Fig. 4 d) to provide sufficient stabilizing effect, without essential hindering of the ion penetration. In addition to the restricting function, conformal $\mathrm{TiO}_{2}$ also provided extra capacity via $\mathrm{Li}^{+}$ intercalation/de-intercalation that alleviated the water electrolysis, as illustrated in Fig. 4e. As expected, excellent cycling performance of the $\mathrm{Fe}_{3} \mathrm{O}_{4} @ \mathrm{TiO}_{2}$ electrode up to 30,000 cycles was achieved (Fig. 4f). Nevertheless, the remaining challenge for the ALD-decorated iron oxide anode is that it takes a longer time to be fully activated.

Similar to iron oxides, $\mathrm{Bi}_{2} \mathrm{O}_{3}$ can also store charges in basic electrolytes via multi-electron Faradic processes $\left(\mathrm{Bi}_{2} \mathrm{O}_{3}+3 \mathrm{H}_{2} \mathrm{O}\right.$ $\left.+6 \mathrm{e}^{-} \rightleftharpoons 2 \mathrm{Bi}^{0}+6 \mathrm{OH}^{-}\right)$, and due to its low redox potential, it has also been used as the anode material in alkaline batteries and AHSCs. Recent advances have demonstrated that direct growth of arrayed $\mathrm{Bi}_{2} \mathrm{O}_{3}$ architectures on the current collector (e.g.,

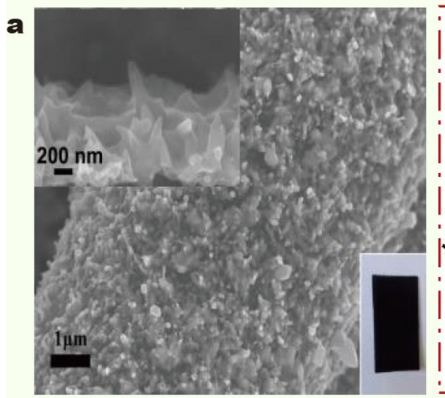

b Carbon glue protection
(i) Sufficient buffering of volume change

(ii) Continuous electron transport
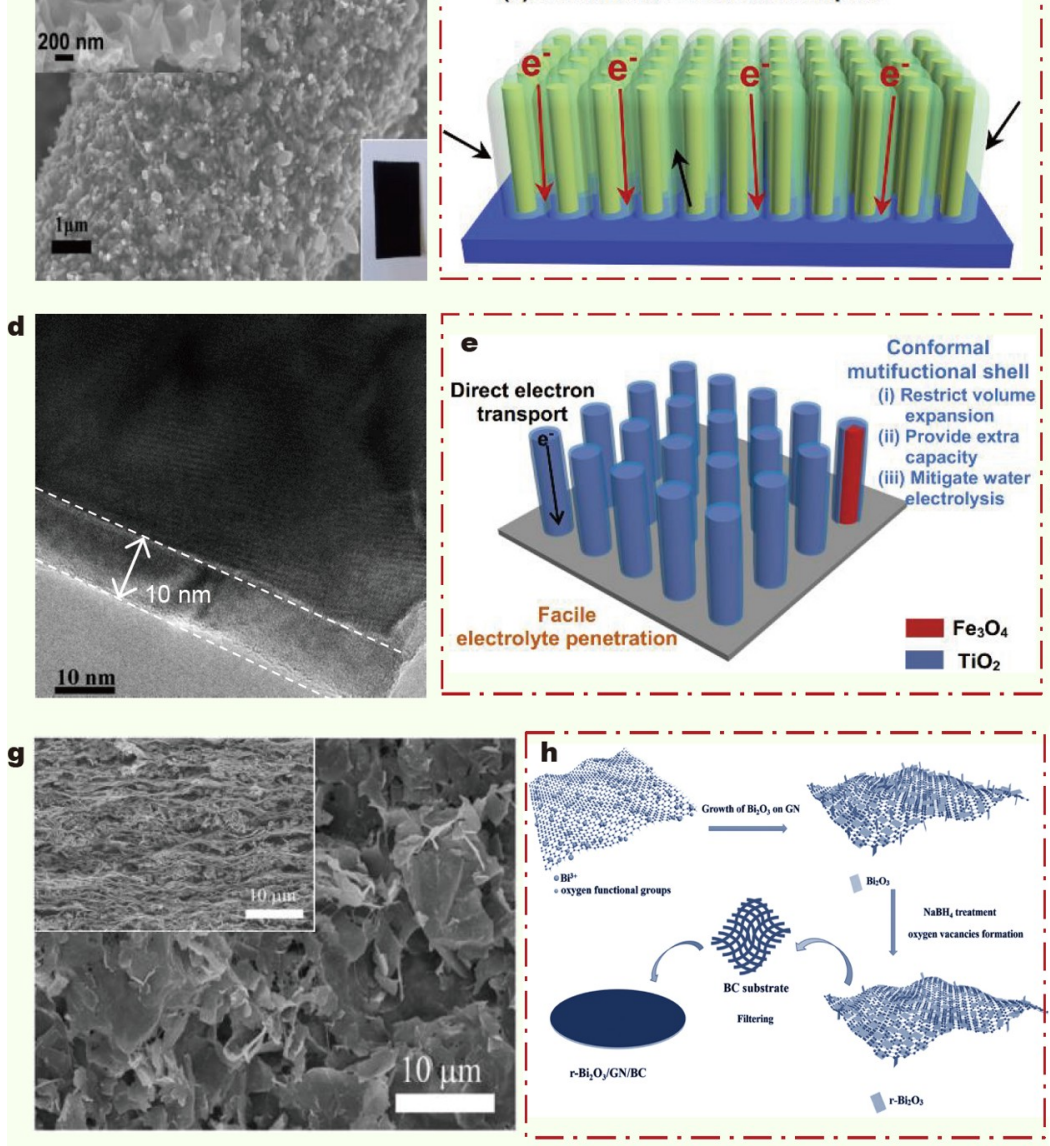
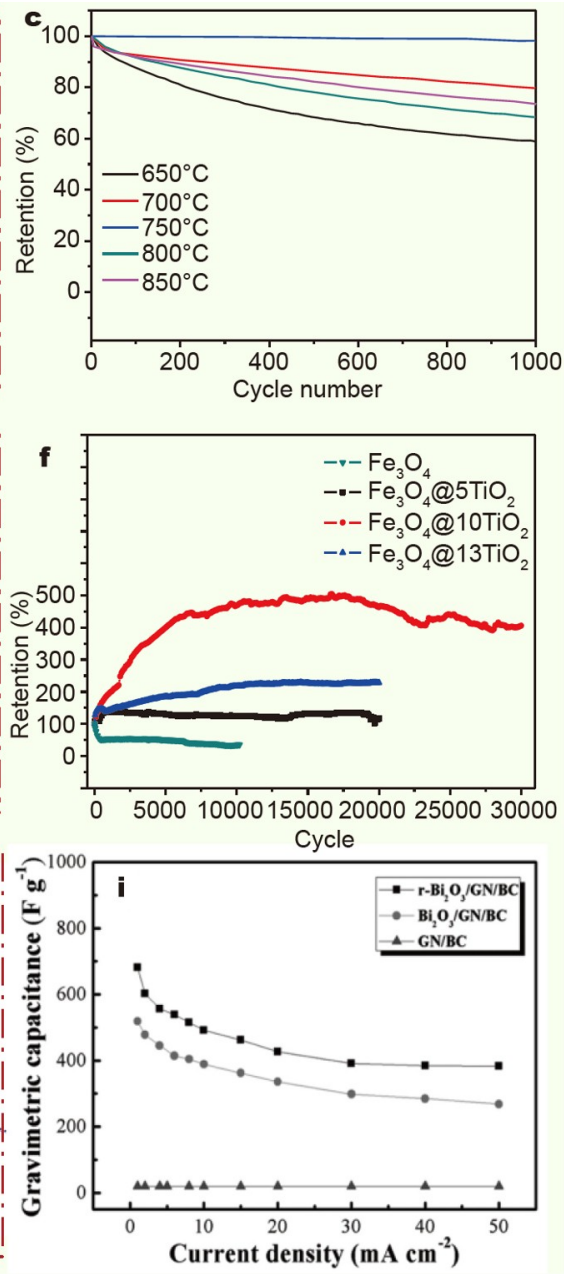

Figure 4 (a-c) SEM images, the features and cycling performance of $\mathrm{Fe}_{3} \mathrm{O}_{4} @$ carbon glue. Reprinted with permission from Ref. [104], Copyright 2018, Wiley. (d-f) TEM images, structural features and cycling performance of the $\mathrm{Fe}_{3} \mathrm{O}_{4} @ \mathrm{ALD} \mathrm{TiO}_{2}$. Reprinted with permission from Ref. [106], Copyright 2018, Wiley. (g, h) SEM and the synthesis route of $\mathrm{r}-\mathrm{Bi}_{2} \mathrm{O}_{3} / \mathrm{GN} / \mathrm{BC}$. (i) Gravimetric capacity of $\mathrm{r}-\mathrm{Bi}_{2} \mathrm{O}_{3} / \mathrm{GN} / \mathrm{BC}, \mathrm{Bi}_{2} \mathrm{O}_{3} / \mathrm{GN} / \mathrm{BC}$, and GN/BC versus different current densities. Reprinted with permission from Ref. [46], Copyright 2017, Wiley. 
nanosheet arrays) can lead to the achievement of high capacity and significant enhancement in the rate performance $[107,108]$. Following this concept, a vertically aligned $\mathrm{Bi}_{2} \mathrm{O}_{3}$ anode with good crystallinity was further fabricated, which could maintain high-capacity retention of $42.2 \%$ when the current density increased 10-fold [109]. Besides arrayed architectures, freestanding electrode can also improve the performance via forming a network with mixed ionic/electronic conductivity. For instance, Liu et al. [46] reported the fabrication of freestanding oxygen-defective bismuth oxide $\left(\mathrm{r}-\mathrm{Bi}_{2} \mathrm{O}_{3}\right)$ /graphene $(\mathrm{GN}) / \mathrm{bac}$ terial cellulose (BC) electrode with high mass loading $\left(9.8 \mathrm{mg} \mathrm{cm}^{-2}\right)$, which was achieved through a simple solvothermal process and subsequent $\mathrm{NaBH}_{4}$ reduction (Fig. $4 \mathrm{~g}, \mathrm{~h}$ ). With strong reductive agent treatment $\left(\mathrm{NaBH}_{4}\right.$ solution), $\mathrm{r}-\mathrm{Bi}_{2} \mathrm{O}_{3} / \mathrm{GN} /$ $\mathrm{BC}$ acquired abundant oxygen vacancies and endowed $\mathrm{Bi}_{2} \mathrm{O}_{3}$ with richer active sites and faster charge transfer. As a result, the electrode could achieve $83 \%$ of the theoretical value and better rate performance than previously reported $\mathrm{Bi}_{2} \mathrm{O}_{3}$ electrodes (Fig. 4i). Despite significant progress in recent years, $\mathrm{Bi}_{2} \mathrm{O}_{3}$ anode is still far from satisfactory for AHSCs owing to its intrinsically poor conductivity and unstable structure arising from volume expansion during prolonged cycling. Doping, surface modification, and advanced structural design processes carried on other battery-type electrodes are believed to be effective for $\mathrm{Bi}_{2} \mathrm{O}_{3}$ to address these issues.

\section{Battery electrodes for acidic AHSCs}

Aqueous batteries using acidic electrolytes such as the state-ofthe-art lead-acid batteries have been developed over one and a half century. The technique for lead-acid batteries is quite mature and has been widely used in various fields such as transport vehicles, telecommunications and information technologies. The hybridization of lead-acid battery with SC gives birth to acidic AHSCs, which is a type of $\mathrm{AH}$ device defined in our previous review [26]. In recent years, various acidic AHSCs were assembled by using lead dioxide $\left(\mathrm{PbO}_{2}\right)$ and carbon materials as the positive electrode and negative electrode, respectively, due to high voltage $(\sim 2 \mathrm{~V})$ of the device and low cost of carbon [110-114]. In general, such acidic AHSCs demonstrated acceptable comprehensive performance and many literatures dealt with the morphological and structural design of $\mathrm{PbO}_{2}$ cathode and carbon anode. However, long-term cycling was still limited owing to the $\mathrm{PbO}_{2}$ being sulfated during the charge storage process. The issue of the sulfated $\mathrm{PbO}_{2}$ could be overcome by using methane sulfonic acid electrolyte instead of sulfuric acid. For example, Perret et al. [112] reported the $\mathrm{PbO}_{2} / /$ AC AHSCs that showed 5000 charge/discharge cycles at $22 \mathrm{C}$ rate without any sign of performance degradation in methane sulfonic acid electrolyte. Moreover, increasing the active surface area of $\mathrm{PbO}_{2}$ electrode is believed to enhance the material utilization and thus increase the capacity of the system $[114,115]$. For instance, Zhang et al. [116] developed a unique 3D-Ti/ $\mathrm{PbO}_{2}$ positive electrode for acidic AHSCs. The electrode material was synthesized by anodic oxidation on $3 \mathrm{D}$ porous conductive substrates, which enabled the in situ oxidation of $\mathrm{Pb}^{2+}$ to $\mathrm{PbO}_{2}$ directly on the current collector. Based on the $3 \mathrm{D}$ porous $\mathrm{Ti}$ substrates with larger surface area and good electrical conductivity, the generated $3 \mathrm{D}-\mathrm{Ti} / \mathrm{PbO}_{2}$ could deliver significantly higher capacity of $132 \mathrm{~mA} \mathrm{~h}^{-1}$ than $\mathrm{Ti}-\mathrm{PbO}_{2}\left(20.8 \mathrm{~mA} \mathrm{~h} \mathrm{~g}^{-1}\right)$. Furthermore, the acidic 3D-Ti/ $\mathrm{PbO}_{2} / / \mathrm{AC}$ AHSCs was assembled based on $3 \mathrm{D}-\mathrm{Ti} / \mathrm{PbO}_{2}$ as the positive electrode and $\mathrm{AC}$ as the negative electrode, which displayed good rate performance with an energy density of $30 \mathrm{Wh} \mathrm{kg}^{-1}$ at a power density of $2078 \mathrm{~W} \mathrm{~kg}^{-1}$ and stable cycling stability with capacitance retention of $\sim 100 \%$ after 1000 cycles.

\section{DESIGN OF CAPACITIVE ELECTRODES IN AHSCs}

Being opposite to battery-type electrode, capacitive electrode is also crucial to the device performance of AHSCs. Basically, comparable stored charges per electrode area are the prerequisite to achieve reliable matching with battery-type electrode. Recent years have witnessed significant progress in improving the charge storage capability of capacitive electrode in AHSCs. Tuning the pore structure and size of pure EDLC materials (in particular, conductive carbons) to efficiently utilize pores of different size scales (including micropores) has been demonstrated to be an effective method [117]. For pseudocapacitive materials, the most popular way to attain high capacitance is to design elaborated mico-nanostructures capable of providing more active surfaces or interfaces for Faradaic reactions [118]. Other key strategies reported in recent years are: (1) tuning the surface chemistry to enhance electrolyte infiltration and doping EDLC materials to introduce pseudocapacitive contribution; (2) exploration of new-types of EDLC and pseudocapacitive materials (Fig. 1, left side).

\section{Traditional capacitive materials}

Carbon-based materials as traditional capacitive materials have been well developed due to the advantages of large specific surface area and good electronic conductivity. The capacitance of carbon materials is attributed to charge accumulation on the material surface via physical adsorption to form EDLC. However, the specific surface area of the carbon electrode is theoretically restricted to $2630 \mathrm{~m}^{2} \mathrm{~g}^{-1}$ [119], which limits the theoretical capacitance. Moreover, the voltage of device is generally below $2.0 \mathrm{~V}$ in aqueous electrolyte. Limited capacitance and device voltage lead to unsatisfactory energy density of AHSCs when carbon-based capacitive electrodes are employed. To address the challenge, some studies have concentrated on heteroatom $(\mathrm{N}, \mathrm{O}, \mathrm{B}, \mathrm{S}$, etc.) doping of carbon materials to increase the capacitance $[89,120-122]$. The introduction of elemental dopants may enhance the wettability of material surface, increase the electronic conductivity, or induce pseudocapacitance via Faradaic reactions of dopants with species in aqueous electrolytes. Consequently, in general, doped carbon electrodes store charges based on a mixed mechanism.

Different from carbon-based capacitive materials, pseudocapacitive materials have relatively high capacitance as a result of the occurrence of dominant redox reactions on the surface or near-surface. Typical materials are $\mathrm{RuO}_{2}$ [123], $\mathrm{MnO}_{2}$ [124], $\mathrm{V}_{2} \mathrm{O}_{5}$ [125], $\mathrm{MoS}_{2}$ [126], $\mathrm{MoO}_{2}$ [127], and conducting polymers such as poly(3,4-ethylenedioxythiophene) (PEDOT) [128], PANI [129], and PPy [130]. Among them, metal oxides constitute one promising category that has been widely investigated in recent years; nevertheless, metal oxide materials suffer from poor electronic conductivity and relatively limited cycling stability. Thus, much attention has been paid to boosting the electrochemical performance by coating conducting polymers or carbon-based materials [125,131-133]. The on-purpose designed surface materials not only serve as a conducting agent in the electrodes, but also help to alleviate the structural collapses of the inner metal oxides. A good example was demonstrated by 
$\mathrm{Qu}$ et al. [125], who fabricated a core-shell structure of PPy grown on $\mathrm{V}_{2} \mathrm{O}_{5}$ nanoribbon using anionic dodecylbenzenesulfonate $\left(\mathrm{DBS}^{-}\right)$as a surfactant (Fig. 5a, b). Pyrrole monomer was first adsorbed on the $\mathrm{V}_{2} \mathrm{O}_{5}$ surface via electrostatic interaction between anionic $\mathrm{DBS}^{-}$and protonated pyrrole. Then, the core-shell electrode architecture was attained after adding $\mathrm{FeCl}_{3}$ solution dropwise to ensure the oxidative polymerization of pyrrole. As expected, the structure of $\mathrm{PPy@} \mathrm{V}_{2} \mathrm{O}_{5}$ electrode exhibited no evident changes during cycling based on the XRD results at different cycling states (Fig. 5c) and this electrode demonstrated extremely long cycling stability of up to 10,000 cycles. In general, conductive material coating gives similar effect on the electrochemical performance for other metal oxide pseudocapacitive materials. It has been further proven that the combined use of free-standing oxide electrode architecture can maximize the coating benefits and aid in achieving outstanding capacitive charge storage performance $[71,86]$.

\section{Metal carbides/nitrides (MXenes)}

To fulfil the demands of developing high-energy AHSCs, new
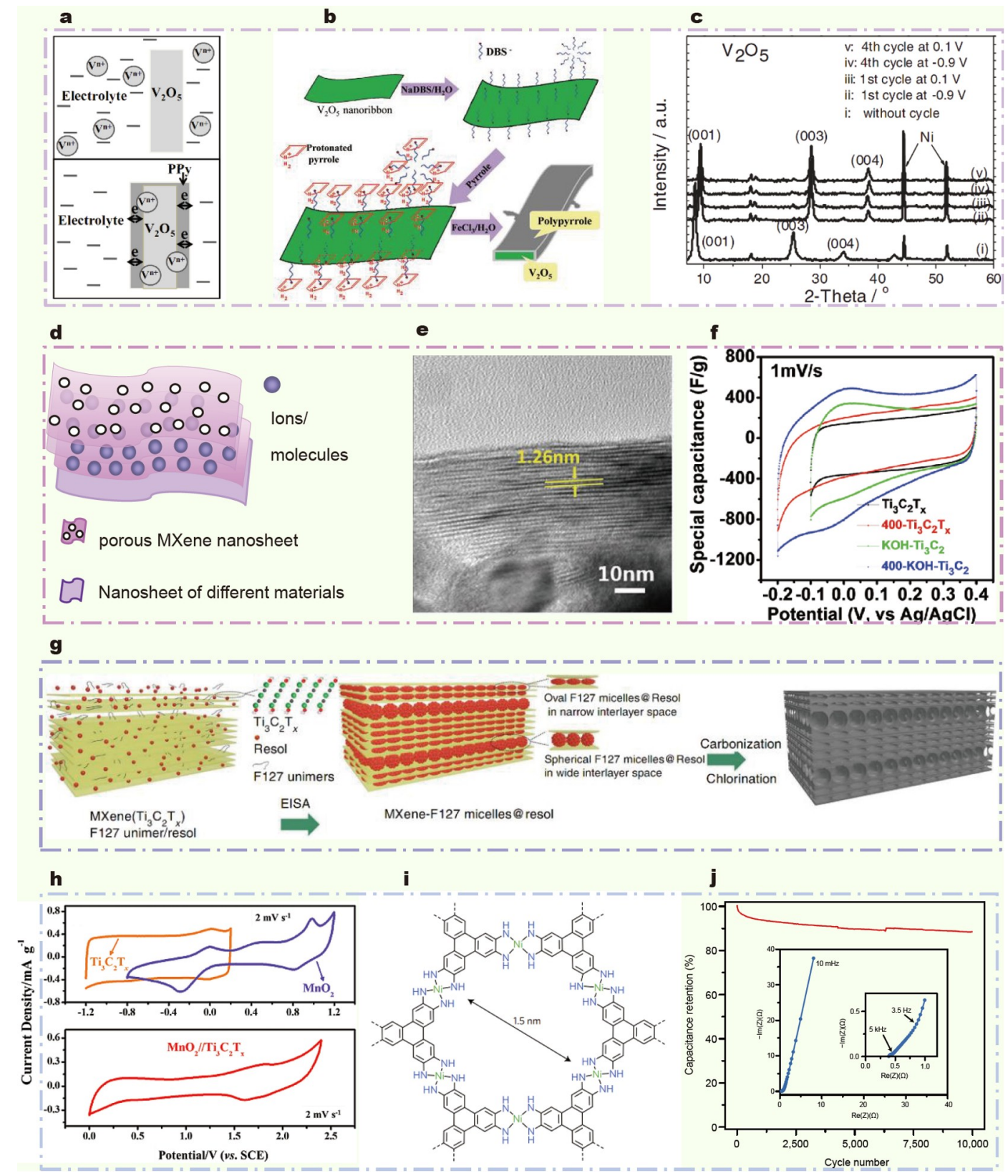

Figure 5 (a, b) Schematic illustration of PPy growth and coating on $\mathrm{V}_{2} \mathrm{O}_{5}$. (c) Ex situ XRD of the PPy@ $\mathrm{V}_{2} \mathrm{O}_{5}$ electrodes. Reprinted with permission from Ref. [125], Copyright 2012, Wiley. (d) Schematic of hybrid structures composed of two types of interleaved nanosheets and intercalated ions or molecules. (e, f) TEM images and CV of 400-KOH-Ti $\mathrm{C}_{2}$. Reprinted with permission from Ref. [140], Copyright 2017, Wiley. (g) Schematic illustration of the synthetic route of MXene-based hybrid with 2D ordered mesoporous carbon. Reprinted with permission from Ref. [142], Copyright 2017, Nature Publishing Group. (h) CV curves of the $\mathrm{Ti}_{3} \mathrm{C}_{2} \mathrm{~T}_{x}, \mathrm{MnO}_{2}$ and $\mathrm{MnO}_{2} / / \mathrm{Ti}_{3} \mathrm{C}_{2} \mathrm{~T}_{x}$ electrodes. Reprinted with permission from Ref. [145], Copyright 2017, Wiley. (i) Molecular structure of $\mathrm{Ni}_{3}(\mathrm{HITP})_{2}$. (j) Repeated cycling at $2 \mathrm{Ag}^{-1}$ and Nyquist plot of $\mathrm{Ni}_{3}(\mathrm{HITP})_{2}$. Reprinted with permission from Ref. [149], Copyright 2017, Nature Publishing Group. 
types of pseudocapacitive materials have also been discovered. Among them, transition metal carbides and nitrides (MXenes) have been attracting extensive attention due to their multiple advantages such as metallic conductivity, interlayer structure, and hydrophilic nature of the functionalized surface [134]. MXenes are generally synthesized by selectively etching the A element layers from the ternary carbides and nitrides $\mathrm{M}_{n+1} \mathrm{AX}_{n}$ with a general formula of $\mathrm{M}_{n+1} \mathrm{X}_{n} \mathrm{~T}_{x}$, where $\mathrm{M}$ is an early transition metal, $\mathrm{X}$ is carbon $(\mathrm{C})$ or nitrogen $(\mathrm{N}), \mathrm{T}$ represents surface functional groups $(-\mathrm{O},-\mathrm{OH}$, and $-\mathrm{F})$, and $n=1$ to 3 . To certain extent, MXenes may replace carbon-based materials for use in aqueous energy storage devices because of their ultrahigh electronic conductivity of up to $150,000 \mathrm{~S} \mathrm{~m}^{-1}$ and large specific surface area, which in principle can result in significant value of capacitance of EDLC $[135,136]$. Besides, various cations $\left(\mathrm{Na}^{+}\right.$, $\mathrm{K}^{+}, \mathrm{NH}_{4}^{+}, \mathrm{Mg}^{2+}, \mathrm{Sn}^{4+}$ ) [137,138], cationic surfactant (cetyltrimethylammonium bromide (CTAB)) [139], and other functional pillared materials [140-142] can be intercalated into MXene layers to stabilize the layered slabs (maintain the high surface area and nanosheet active edges) and tune the interlayer spacing. These ion- or molecule-intercalated MXenes have thus exhibited significantly improved performance via an alternative charge storage mechanism termed as "intercalation pseudocapacitance" [143,144]. Moreover, MXene nanosheets can be designed with pores for a large amount of ion accumulation or fast ion diffusion and be assembled with nanosheets of other components to synergistically improve energy storage capability (Fig. 5d) [134].

For instance, a pillared $\mathrm{Ti}_{3} \mathrm{C}_{2} \mathrm{~T}_{x}$ MXene $\left(400-\mathrm{KOH}-\mathrm{Ti}_{3} \mathrm{C}_{2}\right)$ was fabricated via cation intercalation and terminal group $\left(\mathrm{OH}^{-} / \mathrm{F}^{-}\right)$ removal [140]. The interlayer distance was increased to $1.26 \mathrm{~nm}$ (initial $\mathrm{Ti}_{3} \mathrm{C}_{2}: 0.96 \mathrm{~nm}$ ) after the synthesis, as shown in Fig. $5 \mathrm{e}$. The increase of interlayer spacing in $\mathrm{Ti}_{3} \mathrm{C}_{2} \mathrm{~T}_{x}$ facilitated the charge transport and led to the participation of more $\mathrm{Ti}$ atoms in redox pseudocapacitive reactions. Therefore, $400-\mathrm{KOH}-\mathrm{Ti}_{3} \mathrm{C}_{2}$ delivered the highest capacitance of $500 \mathrm{Fg}^{-1}$ at the scan rate of $1 \mathrm{mV} \mathrm{s}^{-1}$ compared with other samples reported in literature studies (Fig. 5f). As a promising capacitive material, MXene has also been widely utilized to mix with metal oxides $\left(\mathrm{MnO}_{x}\right.$, $\mathrm{MoO}_{3}, \mathrm{NiO}$, etc.) to form MXene-based hybrids. Such hybrid capacitive electrodes can take full advantage of the high conductivity of MXenes and high capacitance of metal oxides. In order to avoid the natural restacking of MXene nanosheets, hybrid layered materials with an alternative component structure can be designed. As a demonstration, layer-by-layer motif architectures were synthesized by introducing F127 (amphiphilic triblock copolymer) spherical micelles and low-molecularweight phenolic resoles into the interlayer space of MXene nanosheets via the hydrogen bonding interaction [142]. Fig. 5g schematically illustrates the synthetic route, exhibiting that $2 \mathrm{D}$ ordered mesoporous carbon (OMC) was derived by high-temperature carbonization and further removal of the metal elements via chlorination. The finally obtained OMC layers intercalated with the MXene-derived carbon (MDC) layers, which not only prevented restacking, but also facilitated ion diffusion and electron transfer. Consequently, MDC-OMC electrode achieved a high volumetric capacitance of $212 \mathrm{~F} \mathrm{~cm}^{-3}$ at $0.5 \mathrm{~A} \mathrm{~g}^{-1}$, better than most of the carbon materials reported previously.

With relatively high specific capacitance, MXenes are promising capacitive electrode to couple with battery-type electrode for constructing AHSCs. Zhu et al. [145] reported that the CV curve of $\mathrm{Ti}_{3} \mathrm{C}_{2} \mathrm{~T}_{x}$ anode possessed highly capacitive behavior in $\mathrm{Na}_{2} \mathrm{SO}_{4}$ electrolyte (Fig. 5h). The weak Faradaic peaks observed in the rectangular curve were attributed to the intercalation of $\mathrm{Na}^{+}$into the 2D interlayer of MXene, which can be expressed as follows: $\mathrm{Ti}_{3} \mathrm{C}_{2} \mathrm{~T}_{x}+y \mathrm{Na}^{+}+y \mathrm{e}^{-} \rightarrow \mathrm{Na}_{y} \mathrm{Ti}_{3} \mathrm{C}_{2} \mathrm{~T}_{x}$. Furthermore, an AHSC device using $\mathrm{MnO}_{2}$ as the positive electrode and $\mathrm{Ti}_{3} \mathrm{C}_{2} \mathrm{~T}_{x}$ as the negative electrode was assembled, which demonstrated a capacitive feature with a high voltage of $2.4 \mathrm{~V}$ (Fig. $5 \mathrm{~h}$ ). In the device assembly, $\mathrm{MnO}_{2}$ was applied within a relatively wide potential range as a battery-type electrode (with obvious redox peaks); however, its stored charges did not match well with $\mathrm{Ti}_{3} \mathrm{C}_{2} \mathrm{~T}_{x}$ anode, as shown in Fig. 5h (upper). This explains the distorted rectangular CV profile of the full-cell device (Fig. 5h, bottom). Nevertheless, the couple of pseudocapacitive electrode and battery-type electrode is quite promising for potentially improving the energy density of AHSCs [26], and the performance of $\mathrm{MnO}_{2} / / \mathrm{Ti}_{3} \mathrm{C}_{2} \mathrm{~T}_{x}$ AHSC can principally be further optimized via tuning the mass loading and redox potential window of the two electrodes.

\section{Metal-organic frameworks}

Another new class of capacitive materials are metal-organic frameworks (MOFs), which are crystalline porous materials with high surface area exceeding that of AC. MOFs have demonstrated great application potentials in several fields such as catalysis, semiconductors, and adsorbents due to their large surface area, tunable pore size, and diverse structures [146-148]. Featured with controllable pore size and redox sites, some MOFs are also expected to be used in SCs. Unfortunately, MOF materials generally demonstrate inherent poor electronic conductivity that hinders the electron transport efficiency. Synthesis of conducting MOFs is of extreme importance to overcome this limitation. A typical demonstration was the design of $\mathrm{Ni}_{3}(2,3,6,7,10,11$-hexaiminotriphenylene $)_{2}\left(\mathrm{Ni}_{3}(\mathrm{HITP})_{2}\right)$ with high electronic conductivity, which was further utilized to assemble an SC made entirely from neat MOFs as active materials without any conductive additives and binders [149]. Interestingly, the as-grown $\mathrm{Ni}_{3}(\mathrm{HITP})_{2}$ was composed of stacked $\pi$-conjugated 2D layers with 1D cylindrical channels of $\sim 1.5 \mathrm{~nm}$ diameter (Fig. 5i), showing high electronic conductivity $\left(\sim 5000 \mathrm{~S} \mathrm{~m}^{-1}\right.$; exceeding those of ACs and holey graphite) and spacious space to accommodate large electrolyte ions used in EDLCs. At the low discharge rate of $0.05 \mathrm{~A} \mathrm{~g}^{-1}, \mathrm{Ni}_{3}(\mathrm{HITP})_{2}$ EDLC displayed a gravimetric capacitance of $111 \mathrm{Fg}^{-1}$, which was comparable to that of the state-of-the-art $\mathrm{AC}$ and higher than that of carbon nanotubes (CNTs). Moreover, $\mathrm{Ni}_{3}(\mathrm{HITP})_{2}$-based SCs exhibited a very high surface area-normalized capacitance of $18 \mu \mathrm{F} \mathrm{cm}^{-2}$ and very low equivalent series resistance, as well as capacity retention higher than $90 \%$ over 10,000 cycles (Fig. 5j).

It is envisaged that conductive MOF-based capacitive electrodes with large specific capacitance are quite promising for potential use in future AHSCs. In addition to contributing EDLC capacitance via accumulation of charges in the regular structural pores, it is also possible that MOFs exhibit pseudocapacitive charge storage ability upon ion uptake accompanied with mild Faradaic reactions. Nevertheless, intense redox reaction with ion insertion into pores of MOFs can lead to a batterytype charge storage mechanism [150]. In this case, MOFs may also be utilized to construct AHSCs, but may not serve as a capacitive electrode any more. Storing charges in MOFs based 
on bulk redox reactions is likely to destroy the uniform pore structure due to the significant valence change of metal ions for compensating charges; consequently, issues related to their cycling stability emerge. It therefore seems that pristine MOFs are more suitable to be utilized as capacitive (EDLC or pseudocapacitive) electrode materials.

\section{DESIGN OF ELECTROLYTES}

Quasi-solid-state (hydrogel) electrolytes

Electrolyte is the key component in AHSCs that provides an ionic pathway between the battery-type electrode and capacitive electrode. In general, liquid electrolyte can provide rapid ion transport due to its low viscosity and good ability to conduct ions. However, the use of liquid electrolytes limits the development of multifunctional and flexible energy storage devices for applications in flexible and miniaturized electronics because of the leakage risk under various mechanical strains and working temperatures [151]. In this case, quasi-solid-state (hydrogel) electrolytes provide promising opportunity to solve the abovestated critical issue, which not only retains the advantage of liquid electrolyte to provide sufficient ionic conductivity and ensures intimate interfacial contact, but also inherits the relatively high mechanical property of solid polymer electrolytes.

Our group once developed a quasi-solid-state ultrathin AHSC device with a total thickness of $\sim 40 \mu \mathrm{m}$, which consisted of vanadium oxide nanoarray electrodes and gel (polyvinyl alcohol (PVA)) electrolytes (Fig. 6a) [152]. With the utilization of hydrogel electrolytes and nanoarray architecture, the negative electrode and positive electrode were densely integrated to obtain a thin AHSC device. As expected, the device demonstrated good rate capability (Fig. 6b). Moreover, another quasisolid-state AHSC displayed excellent flexibility [104]. CVs of the device at different bending angles $\left(30^{\circ}-180^{\circ}\right)$ were still able to maintain similar profile (Fig. 6c). Fig. $6 \mathrm{~d}$ shows the EIS results, exhibiting that Nyquist plots of the device changed a little with shape deformation, indicating that the ion diffusion process was not significantly influenced. The outstanding mechanical endurance of the device stemmed from the full integration of gel electrolyte into a $3 \mathrm{D}$ nanoarray electrode, which was believed to buffer the generated stress upon severe bending, avoiding the formation of cracks that would happen in the case of dense films with liquid electrolyte. The AHSC device further endured high pressures of up to $\sim 32.9 \mathrm{kPa}$ and worked well within a wide temperature window of $20-80^{\circ} \mathrm{C}$ (Fig. 6e, f) [105]. These multifunctionalities can be ascribed to the intrinsic merits of gel electrolytes compared with those of conventional liquid electrolytes.

Hydrogel electrolytes consist of salts, polymer, and some amount of water. In principle, the ionic conductivity of hydrogel electrolyte is determined not only by the remaining water, but also by the polymer. Different polymers have different water accommodation abilities and show distinct coordination interactions with metal carrier ions, thus exerting strong influence on the ionic conductivity. The interaction between the polymer and water also significantly impacts the functionality and environmental suitability of electrolytes. In addition to PVA, other polymers such as polyethylene glycol, gelatin, sodium carboxymethylcellulose (CMC), polyacrylamide (PAM), and sodium polyacrylate ( $\mathrm{PANa}$ ) have been extensively investigated for aqueous energy storage in recent years [151]. As an example, a new gel electrolyte utilizing PANa as superabsorbent polymer endowed a $\mathrm{Zn}^{2+}$ storage device with a high ionic conductivity and water-retaining capability [153]. This superabsorbent polymer consists of a 3D crosslinked network, in which hydrophilic groups and organic groups of the carbon chains exhibit the ability of adsorbing and retaining substantial water molecules. In another study, Zhu et al. [154] reported an anti-freezing polyacrylamide hydrogel (PAAm) consisting of cooperative cations (2 $\mathrm{mol} \mathrm{L}^{-1} \mathrm{ZnSO}_{4}$ and $4 \mathrm{~mol} \mathrm{~L}^{-1} \mathrm{LiCl}$ ). The $\mathrm{Zn}^{2+} / \mathrm{Li}^{+}$mixture
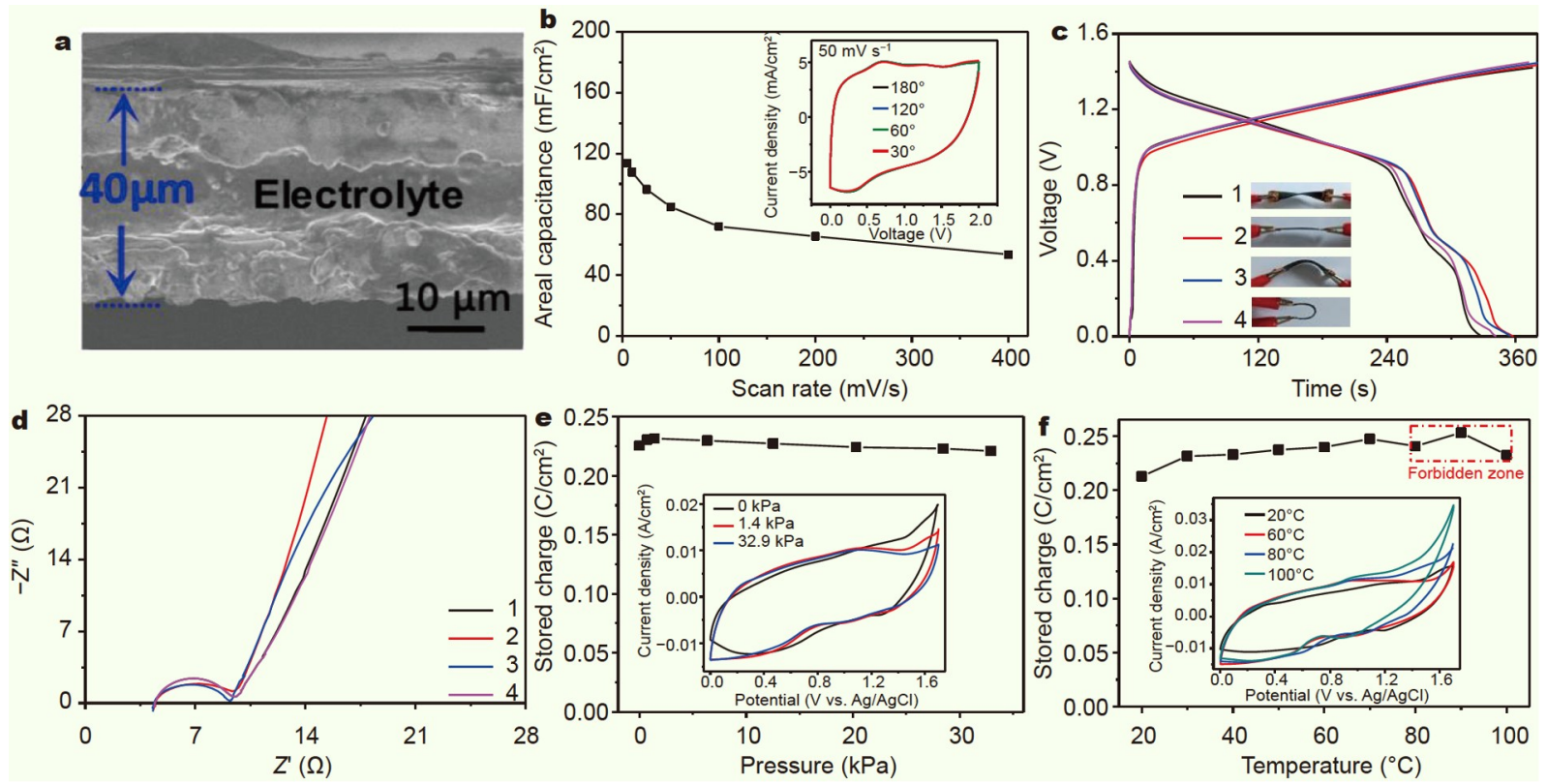

Figure 6 (a) SEM image of the PVA electrolyte. (b) Areal capacitance of the solid-state device. Reprinted with permission from Ref. [152], Copyright 2017, Royal Society of Chemistry. (c) Charge-discharge curves and (d) EIS data at different bending/twisting states of 1-4. Reprinted with permission from Ref. [104], Copyright 2018, Wiley. (e, f) Stored charge variation and CVs at different temperatures and pressures. Reprinted with permission from Ref. [105], Copyright 2015, Wiley. 
cations cooperatively dissociated the intermolecular hydrogen bonding between water molecules by the cooperative hydration, which significantly reduced the freezing temperature of the hydrogel. Consequently, the device could retain $98 \%$ capacity retention upon cooling down to $-20^{\circ} \mathrm{C}$ and showed near $100 \%$ capacity retention with $>99.5 \%$ Coulombic efficiency over 500 cycles at $-20^{\circ} \mathrm{C}$.

\section{High-voltage electrolytes}

Despite the fact that asymmetric device configuration has pushed the voltage window of AHSCs beyond the thermodynamic stability window of water $(1.23 \mathrm{~V})$, the experimentally achieved voltage of AHSCs is still limited $(<2.5 \mathrm{~V})$. This brings a significant challenge on the energy output enhancement. An effective approach proposed in recent years to increase the energy density is the use of "water-in-salt" electrolyte (WISE), which has been mostly applied for various battery devices $[155,156]$. WISEs were first explored by dissolving lithium bis (trifluoromethane sulfonyl)imide (LiTFSI) in water, at extremely high concentrations (molality $>20 \mathrm{~m}$, molality $(m)=$ mole of solute/weight of solvent $\left.\left(\mathrm{mol} \mathrm{kg}^{-1}\right)\right)$ [157]. Interestingly, with this super-concentrated electrolyte, a dense solid electrolyte interphase (SEI with $\mathrm{Li}_{2} \mathrm{CO}_{3}$ and $\mathrm{LiF}$-based components; conducting ions but insulating electrons) was formed on the surface of anode. Moreover, anion-containing $\mathrm{Li}^{+}$solvation sheath also emerged to reduce the water activity, synergistically expanding the electrochemical stability window of the aqueous electrolyte to $\sim 3.0 \mathrm{~V}$ (Fig. 7a-c) [158]. This breakthrough motivated researchers to systematically explore more types of WISEs and utilize them in AHSCs. Consequently, a $\mathrm{Na}^{+}$AHSC using superconcentrated sodium perchlorate $\left(\mathrm{NaClO}_{4}\right)$ as the aqueous electrolyte was reported [159]. The $\mathrm{NaClO}_{4}$ electrolyte with a

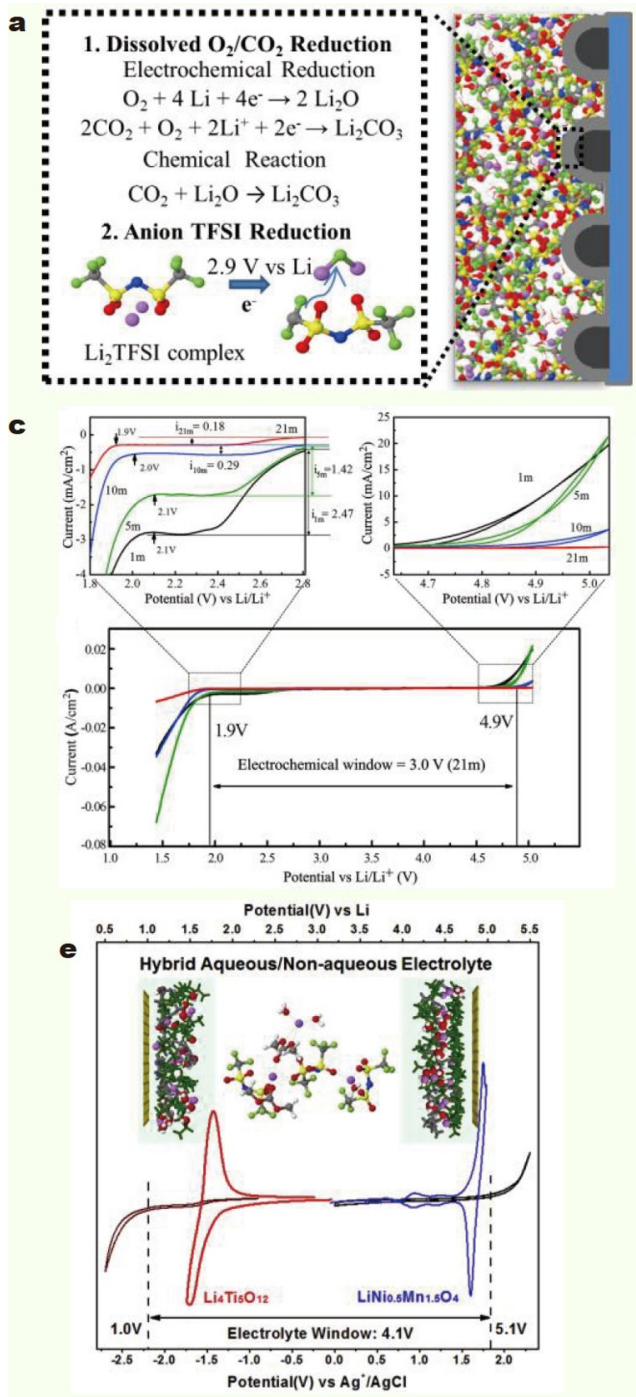

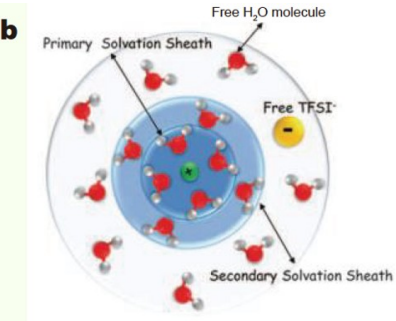

$\left\{\left[\mathrm{Li}\left(\mathrm{H}_{2} \mathrm{O}\right)_{4}\right]\left(\mathrm{H}_{2} \mathrm{O}\right)_{4}\right\}+\mathrm{nH}_{2} \mathrm{O}$ n $\geq 1$ Salt-in-Water

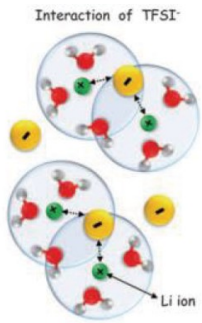

$\mathrm{Li}\left(\mathrm{H}_{2} \mathrm{O}\right)_{2.5}$-TFSI Water-in-Salt
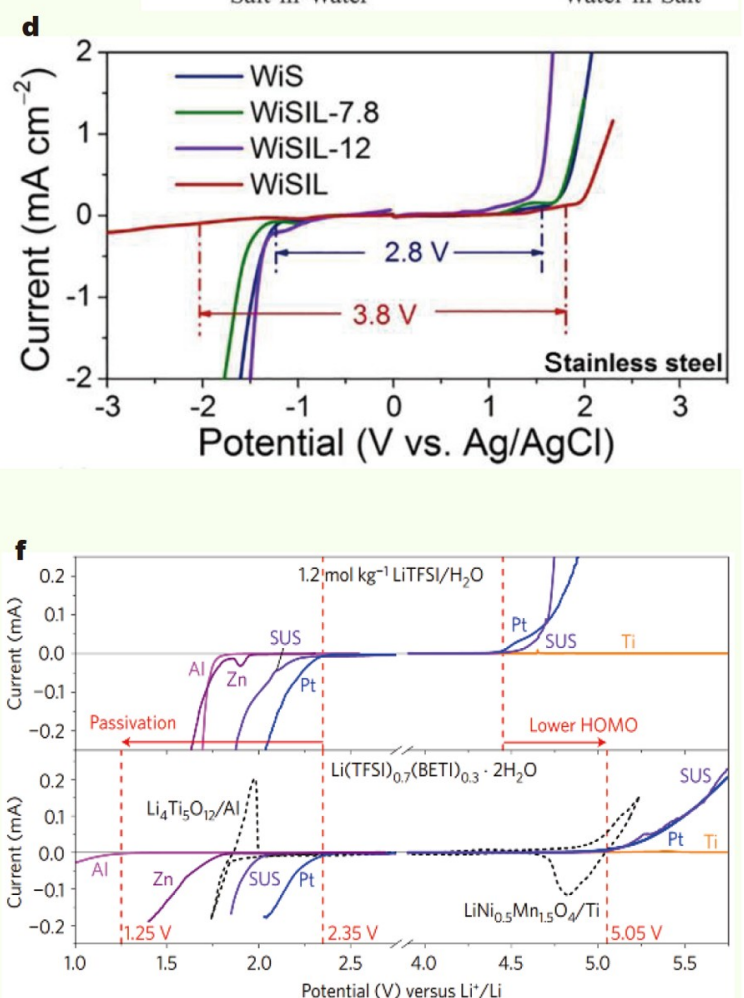

Figure 7 (a) SEI formation mechanisms in WISE. Reprinted with permission from Ref. [158], Copyright 2017, American Chemical Society. (b) Illustration of the evolution of the $\mathrm{Li}^{+}$primary solvation sheath in diluted and WIS solutions. (c) The electrochemical stability window of the LiTFSI- $\mathrm{H}_{2} \mathrm{O}$ electrolytes. Reprinted with permission from Ref. [157], Copyright 2015, American Association for the Advancement of Science. (d) The electrochemical stability windows of the WISIL [LiTFSI/ $\mathrm{H}_{2} \mathrm{O} /(\text { EMIM-TFSI) })_{2.0}$ ]. Reprinted with permission from Ref. [161], Copyright 2020, Elsevier. (e) Electrochemical stability window of the full cell with HANE. Reprinted with permission from Ref. [162], Copyright 2018, Elsevier. (f) Potential window of $\mathrm{Li}(\mathrm{TFSI})_{0.7}(\mathrm{BETI})_{0.3} \cdot 2 \mathrm{H}_{2} \mathrm{O}$ compared with that of a typical $1.2 \mathrm{~m} \mathrm{LiTFSI} / \mathrm{H}_{2} \mathrm{O}$ solution with $\mathrm{Li}_{4} \mathrm{Ti}_{5} \mathrm{O}_{12}, \mathrm{LiCoO}_{2}$ and $\mathrm{LiNi}_{0.5} \mathrm{Mn}_{1.5} \mathrm{O}_{4}$ electrodes. Reprinted with permission from Ref. [163], Copyright 2016, Nature Publishing Group. 
high concentration of $17 \mathrm{~m}$ could enlarge the practical stability window to $\sim 2.75 \mathrm{~V}$. It was reported that all water molecules were incorporated into $\mathrm{Na}^{+}$hydration shells via the coordination of the Lewis-basic oxygen atoms with Lewis-acidic $\mathrm{Na}^{+}$, significantly reducing their activity. Moreover, $\mathrm{Na}_{2} \mathrm{CO}_{3}$ can be detected on the anode surface functioning as an in situ generated SEI to prevent water from transferring electrons with anode, further helping to inhibit water electrolysis [160]. In order to further decrease the water content in the WISEs, "WIS/ionic liquid" electrolyte (WISILE) was developed for ALICs [161]. Less water, LiTFSI, and 1-ethyl-3-methylimidazolium FSI (EMIM-FSI) with a molar ratio of 1:1:2 were utilized. The EMIM-FSI salt can act as a co-solvent to dissolve LiTFSI, thus reducing the water content in the system. Furthermore, the use of the larger sized $\mathrm{EMIM}^{+}$ions with high concentration decreased the distribution of water molecules near the electrode surface, making the decomposition of water molecules more difficult. As expected, the WISILE with inherently moisturetolerant property could expand the electrochemical stability window of the device to $3.8 \mathrm{~V}$ as presented in Fig. $7 \mathrm{~d}$, indicating a $\sim 1.0 \mathrm{~V}$ extension compared with that $(\sim 2.8 \mathrm{~V})$ of the $21 \mathrm{~m}$ WISE.

Noteworthily, the formation of anion-originated SEI is not feasible due to the repulsion of anions by negatively polarized anode surfaces. Therefore, Wang et al. [162] designed a hybrid aqueous/non-aqueous electrolyte (HANE) that could in situ generate hybrid interphase (anion/solvent-originated SEI). HANE combined aqueous solvents (LiTFSI; $\sim 14 \mathrm{~mol} \mathrm{~L}^{-1}$ ) with non-aqueous solvents (dimethyl carbonate (DMC)). This type of hybrid electrolyte could inherit the non-flammability and nontoxicity characteristics from the aqueous system and high electrochemical stability from the non-aqueous system. Moreover, non-aqueous portion (solvent) introduced a secondary ingredient (alkylcarbonate) to the protective interphase on the electrode in addition to the $\mathrm{LiF}$ from anion reduction. During the charging/discharging process, the unusual interphasial structure in HANE was constructed to more effectively block the electron tunnel, while leading to better conduction of $\mathrm{Li}^{+}$across it. Therefore, HANE could even expand the electrochemical window to $4.1 \mathrm{~V}$, as shown in Fig. 7e.

Another hydrate-melt electrolyte using $\mathrm{Li}$ salt hydrate melt can also extend the stability window of aqueous electrolytes to $\sim 3.1 \mathrm{~V}$ [163]. Room-temperature hydrate melts of two specific Li salts were evaluated to explore their optimized eutectic systems with the objective of expanding the voltage range at ambient temperatures. Based on the potential windows evaluated for various metal electrodes by linear sweep voltammetry at a low scan rate $\left(0.1 \mathrm{mV} \mathrm{s}^{-1}\right)$ (Fig. $7 \mathrm{f}$ ), the $\mathrm{Li}(\mathrm{TFSI})_{0.7}(\mathrm{BETI})_{0.3} \cdot 2 \mathrm{H}_{2} \mathrm{O}$ hydrate melt provided a wide potential window of $3.1 \mathrm{~V}$. Hydrate-melt electrolytes are essentially WISEs, considering the mass ratio of salts to water used. Moreover, strong interactions also occur between the salts and limited water, and the interfacial SEI is also formed on the electrode surface during the charge storage process, thus reducing the water activity in the way similar to that in the aforementioned LiTFSI WISEs.

In general, WISEs are too expensive to support the sustainable development of AHSCs, in particular, when using lithium salts. In recent five years, the concept of concentrated electrolytes has been successfully extended to other types of aqueous EESs, such as $\mathrm{Na}^{+}, \mathrm{K}^{+}$, and $\mathrm{Zn}^{2+}$-based energy storage devices [155,156]. Despite considerable progress, huge challenges still remain because of the presence of few salts with extremely high solubility in water, high suitability for SEI chemistry (fluorine-containing salt), and high chemical and electrochemical stability in aqueous environments. The recently developed new class of inert cation-assisted WISE (IC-WISE) has shown great promise to provide more opportunities for relieving the above-stated dilemma. Jiang et al. [164] reported the construction of tetraethylammonium $\left(\mathrm{TEA}^{+}\right)$-assisted WISE to improve the solubility of $\mathrm{Na}^{+}$WISE, showing the highest total salt concentration of $31 \mathrm{~mol} \mathrm{~kg}^{-1}$ (9 $\mathrm{m} \mathrm{NaOTF}+22 \mathrm{~m}$ inert TEAOTF), corresponding to the highest salt/water weight ratio of 7.69. This was attributed to the fact that highly concentrated mixed NaOTF and TEAOTF solutions could generate new ionic structures such as contact ion pairs $(\mathrm{CIP}=32 \%)$ and aggregate pairs (AGG = 13\%). As expected, the $\mathrm{Na}^{+}$IC-WISE could expand the electrochemical window to $3.3 \mathrm{~V}$, with the suppression of transition metal dissolution from the battery-type electrode during cycling. Moreover, using super sucrose electrolyte and molecular crowding electrolyte without the high-concentration salt can also expand the electrochemical stability window of aqueous devices by reducing the amount of free water and destroying the tetrahedral structure (the hydrogen bonds) of free water molecules [49].

So far, high-voltage electrolyte-based AHSCs are still at the infant stage. Several examples reported on using high-concentration electrolytes for AHSCs include $40.4 \mathrm{~m} \mathrm{CH}_{3} \mathrm{COOK}$ and $9.8 \mathrm{~m} \mathrm{CH}_{3} \mathrm{COOLi}$ for ALICs [165], $17 \mathrm{~m} \mathrm{NaClO}_{4}$ for ASICs [160], and $1 \mathrm{~m} \mathrm{Zn}\left(\mathrm{CF}_{3} \mathrm{SO}_{3}\right)_{2}$ for $\mathrm{Zn}^{2+}$ AHSCs [2]. For example, Deng et al. [165] reported a low-cost $\mathrm{LiMn}_{2} \mathrm{O}_{4} / / \mathrm{AC}$ ALIC with a $\mathrm{Li}^{+} / \mathrm{K}^{+}$mixed superconcentrated aqueous electrolyte $(40.4 \mathrm{~m}$ $\mathrm{CH}_{3} \mathrm{COOK}$ and $\left.9.8 \mathrm{~m} \mathrm{CH}_{3} \mathrm{COOLi}\right)$. Fig. $8 \mathrm{a}$ demonstrates that in this electrolyte, one $\mathrm{Li}^{+}$and $\mathrm{K}^{+}$hydration separately required four and five water molecules, and the acetate ions associated water molecules were connected via hydrogen bond. The molar ratio value between water molecules and total cations was determined to be 1.3:1, and thus there existed hardly any free water molecules in the superconcentrated electrolyte. As a result, the limited bonded water was difficult to be oxidized or reduced, resulting in $2.85 \mathrm{~V}$ electrochemical stability window (Fig. $8 \mathrm{~b}$ ). Benefiting from the superconcentrated electrolyte, the asdesigned ALIC was also able to be operated in a wider temperature range compared with that using the conventional lowconcentration electrolyte (Fig. $8 \mathrm{c}$, d). At $60^{\circ} \mathrm{C}$, an energy density as high as $77.9 \mathrm{~W} \mathrm{~h} \mathrm{~kg}^{-1}$ was achieved at the power density of $149.1 \mathrm{~W} \mathrm{~kg}^{-1}$. Another ALIC using WISILE was assembled with $\mathrm{Nb}_{2} \mathrm{O}_{5}$ and $\mathrm{AC}$ as the anode and cathode, respectively, which exhibited ultrastable higher-voltage window of $2.8 \mathrm{~V}$ (Fig. 8e, f) [161]. The charge-discharge curves at different current densities were slightly deviated from the linear profile of an ideal capacitive behavior, a characteristic of a hybrid device. Fig. $8 \mathrm{~g}$ illustrates that the $\mathrm{AC} / / \mathrm{Nb}_{2} \mathrm{O}_{5}$ ALIC still delivered a high energy density of $16.4 \mathrm{~W} \mathrm{~h} \mathrm{~kg}^{-1}$ at the power density of as high as $4.9 \mathrm{~kW} \mathrm{~kg}^{-1}$. The ALIC further exhibited long-term stability for up to 3000 cycles at $1.0 \mathrm{~A} \mathrm{~g}^{-1}$ with nearly $100 \%$ Coulombic efficiency (Fig. 8h)

With the high voltage window enabled by such electrolytes, AHSCs are expected to demonstrate the highest energy density among various types of AHSCs, considering their high capacitance as well. Nevertheless, SCs should also deliver high power density to differentiate them from batteries, and fast ion transport in electrolytes and efficient charge transfer at the electrode/ 

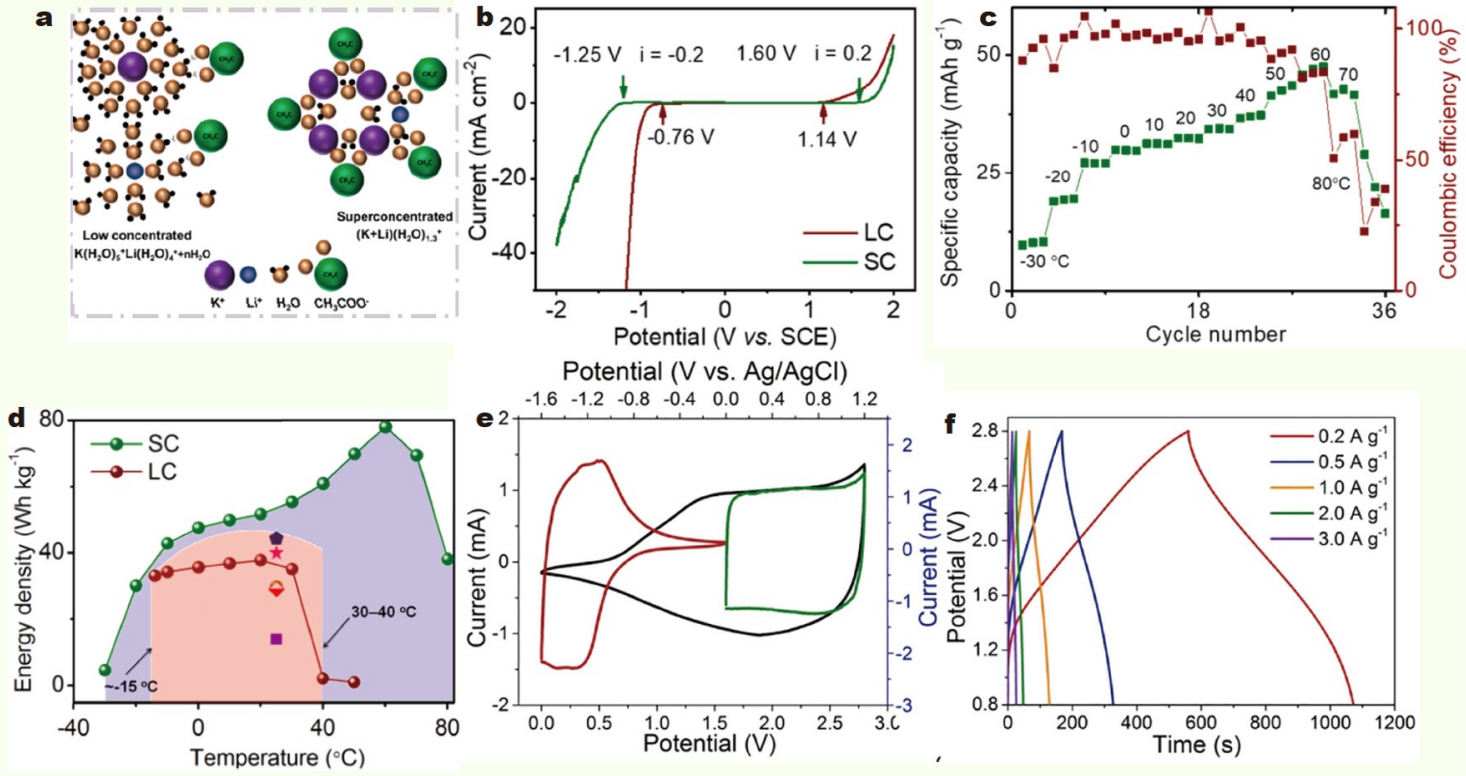

Potential (V vs. Ag/AgCl)
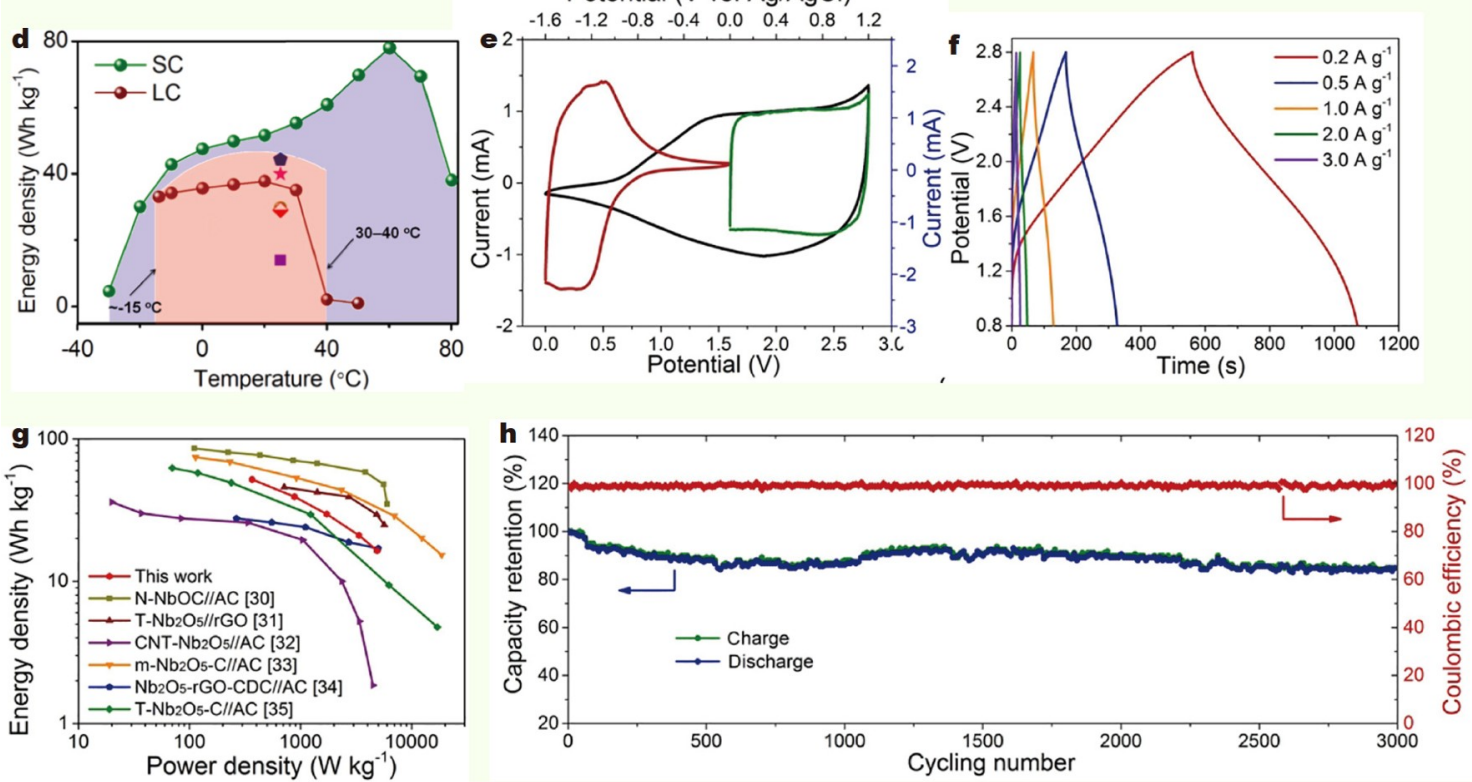

Figure 8 (a, b) Schematic illustration of the cation solvation and electrochemical stability window of the high- and low-concentration electrolytes. (c, d) Specific discharge capacities and the energy density of the ALICs in both the electrolytes at different temperatures. Reprinted with permission from Ref. [165], Copyright 2019, Elsevier. (e-h) Electrochemical performance of the $\mathrm{AC} / / \mathrm{Nb}_{2} \mathrm{O}_{5}$ ALIC device. The numbers in brackets refer to the cited references in Ref. [161]. Reprinted with permission from Ref. [161], Copyright 2020, Elsevier.

electrolyte interface must be ensured. In this regard, special attention should be paid in future to increasing the ionic conductivity of high-voltage aqueous electrolytes, without drastically increasing the viscosity and avoiding the inevitable salt precipitation at low temperatures [49].

\section{NEW CONFIGURATIONS OF AHSCs}

To optimize the electrochemical performance and promote the application potentials of AHSCs, the design of novel device configuration is also of great importance. Till date, new types of AHSCs have rarely been investigated. Nevertheless, there are already related interesting examples reported in literatures. For example, our group constructed a novel all-oxide AHSC using conductive $\mathrm{MoO}_{2}-\mathrm{C}$ as the capacitive negative electrode and $\mathrm{NiCo}_{2} \mathrm{O}_{4}$ as the battery-type positive electrode in aqueous $\mathrm{LiOH}$ electrolyte, showing a unique "dual-ion insertion" energy storage mechanism and good electrochemical performance [166]. Different from the charge storage process in conventional AHSCs, the anode and cathode of $\mathrm{NiCo}_{2} \mathrm{O}_{4} / / \mathrm{MoO}_{2}-\mathrm{C}$ AHSC reversibly intercalate cations $\left(\mathrm{Li}^{+}\right)$and anions $\left(\mathrm{OH}^{-}\right)$, respectively, as illustrated in Fig. 9a. In most alkaline AHSCs using Ni and Cobased cathodes, the coupling anodes are EDLC carbon materials. Herein, instead, the capacitive $\mathrm{MoO}_{2}-\mathrm{C}$ was used, which stored charges via surface/near-surface $\mathrm{Li}^{+}$insertion into $\mathrm{MoO}_{2}$ and thus provided significant pseudocapacitance. Noteworthily, in basic electrolytes, it is difficult to find suitable pseudocapacitive oxide storing charges using $\mathrm{OH}^{-}$(usually battery-type redox reaction), and thus dual-ion utilization has played a critical role in this configuration. As expected, the AHSC device demonstrated quasi-linear charge-discharge profiles (Fig. 9b) and delivered a high energy density and power density $\left(41.8 \mathrm{~W} \mathrm{~h} \mathrm{~kg}^{-1}\right.$ and 19,922.2 $\mathrm{W} \mathrm{kg}^{-1}$ ) (Fig. 9c) compared with AC anode-based alkaline AHSCs.

Another unconventional AHSC is non-polarity structurally symmetric AHSC that can principally be charged in arbitrary direction without specific engineering protection. In 2017, a non-polarity full cell was assembled using conductive vanadium trioxide@carbon $\left(\mathrm{V}_{2} \mathrm{O}_{3} @ \mathrm{C}\right)$ nanosheet arrays as both the anode and cathode [152]. The energy storage mechanisms involved the redox reactions of vanadium ions upon $\mathrm{Li}^{+}$uptake, corresponding to redox couples of $\mathrm{V}^{3+} / \mathrm{V}^{2+}$ and $\mathrm{V}^{4+} / \mathrm{V}^{3+}$ for the anode and cathode, respectively (Fig. 9d). Furthermore, CV profiles shown in Fig. 9e indicate that the redox reaction in the anode dominantly represented battery behavior, while that in the cathode featured pseudocapacitive character. Despite the use of the same material as both electrodes, the charge storage mechanisms are quite different, making the full cell operate like AHSCs. On the other hand, exactly due to the symmetric device 

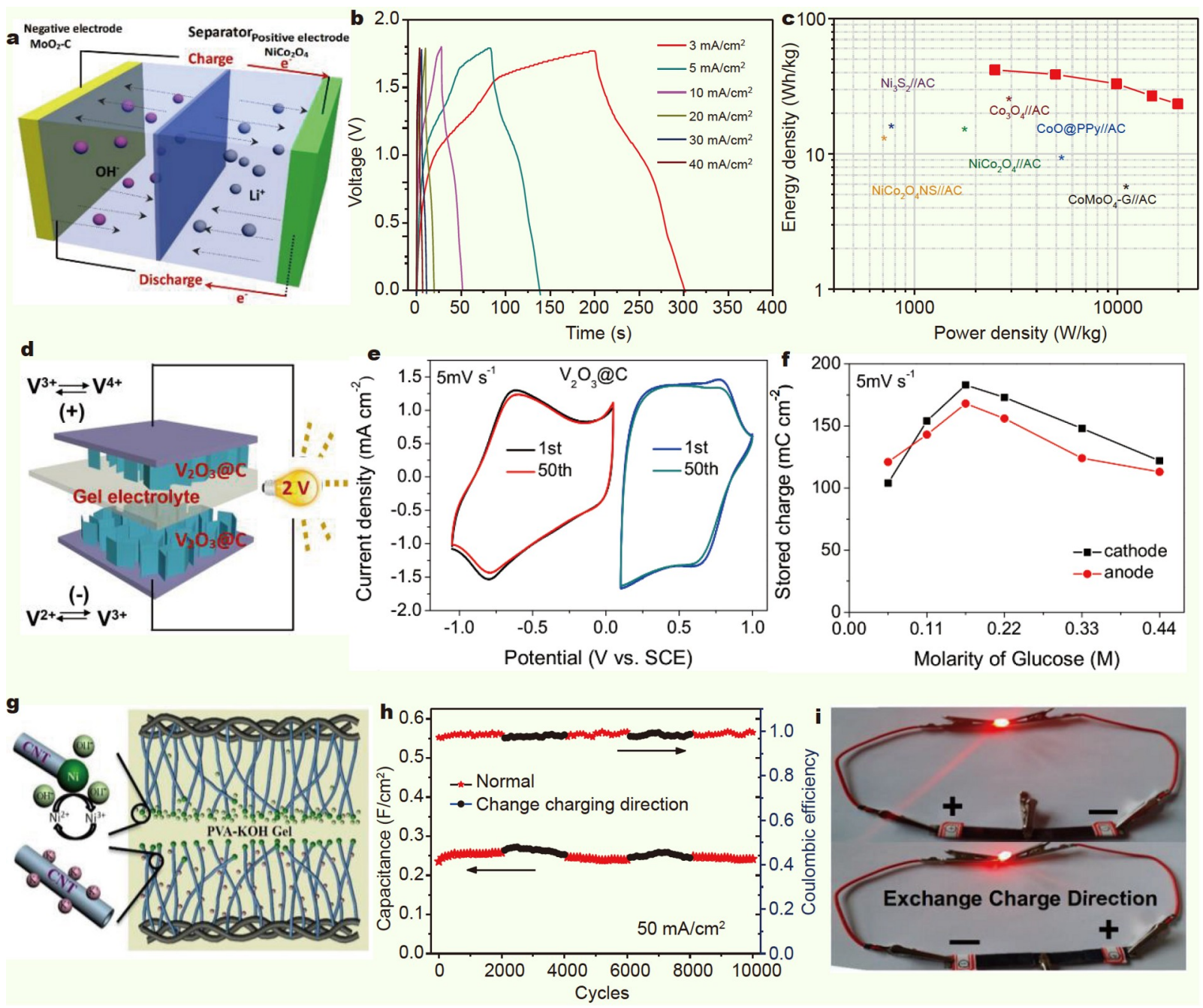

Figure 9 (a) Schematic illustration of the configuration and working mechanism of the AHSC device. (b, c) The charge-discharge curves and Ragone plot of the AHSC device. Reprinted with permission from Ref. [166], Copyright 2016, American Chemical Society. (d) Schematic illustration of the 2.0 V V $\mathrm{O}_{3} @ \mathrm{C} / /$ $\mathrm{V}_{2} \mathrm{O}_{3} @ \mathrm{C}$ device. (e) CVs of the $\mathrm{V}_{2} \mathrm{O}_{3} @ \mathrm{C}$ electrode. (f) Stored charge of the $\mathrm{V}_{2} \mathrm{O}_{3} @ \mathrm{C}$ with different glucose concentrations. Reprinted with permission from Ref. [152], Copyright 2017, Royal Society of Chemistry. (g) Schematic illustration of the charge storage mechanism of the AHSC device. (h, i) Cycling stability and lighting LED indicator, demonstrating the non-polarity feature. Reprinted with permission from Ref. [167], Copyright 2018, Elsevier.

structure, this type of AHSC has no polarity and it is not necessary to point out which side is positive or negative electrode when the cell is fully discharged and ready for next-round charging. The use of the same anode and cathode material to construct AHSCs further brings benefit for acquiring charge balance. Fig. If exhibits that with different carbon coating amounts (via changing glucose concentration), the $\mathrm{V}_{2} \mathrm{O}_{3} @ \mathrm{C}$ anode and cathode always exhibit comparable charge storage ability. Benefiting from the "carbon-protection" effect and the use of PVA-LiCl gel electrolyte, significant alleviation in the vanadium dissolution and structural damage was observed; thus, the charge balance between the two electrodes could be maintained during long-term cycling. Consequently, the device was quite stable and could remain $\sim 93 \%$ of the initial capacitance value upon 6000 cycles at a high current density of $2 \mathrm{~mA} \mathrm{~cm}^{-2}$. Later, non-polarity AHSCs were further developed by using the binder-free nickel nanoparticle@carbon nanotube (Ni@CNT) as both the negative and positive electrodes (Fig. 9g) [167]. This device could readily operate in basic electrolyte with the efficient utilization of the Faradaic redox reactions of $\mathrm{Ni}^{2+} / \mathrm{Ni}^{3+}$ at the positive side and EDLC charge accumulation on CNTs at the negative side. It exhibited good electrochemical stability without capacitance loss after 10,000 cycles with alternative change of the charging direction, indicative of excellent non-polarity feature (Fig. 9h). Moreover, the device could power a 5-mm-diameter round red light-emitting diode indicator (LED; $1.8 \mathrm{~V}, 20 \mathrm{~mA}$ ) after getting charged in two different directions (Fig. 9i).

Compared with the above AHSCs employing monovalent ions, AHSCs with multivalent-ion storage $\left(\mathrm{Zn}^{2+}, \mathrm{Mg}^{2+}, \mathrm{Ca}^{2+}\right.$, $\mathrm{Al}^{3+}$ ) are also under design and development due to the theoretically high energy density resulting from the multielectron redox reaction involved in the battery-type electrode side $[35,36,168-170]$. Among them, $\mathrm{Zn}^{2+}$ AHSCs using $\mathrm{Zn}$ as the anode and capacitive materials as the cathode have been attracting significant research attention because $\mathrm{Zn}$ has a high volumetric capacity of $5855 \mathrm{~mA} \mathrm{~h} \mathrm{~cm}{ }^{-3}$, suitable redox potential $(-0.763 \mathrm{~V}$ versus $\mathrm{SHE})$, and good electrochemical reversibility in aqueous electrolytes [171]. Unfortunately, the development of $\mathrm{Zn}^{2+}$ AHSCs has been hindered by several factors. For the battery-type electrode, the dendrite growth still exists during plating 
and stripping, leading to safety issues and cycling instability of $\mathrm{Zn}^{2+}$ AHSCs. Moreover, the sluggish $\mathrm{Zn}^{2+}$ diffusion kinetics of $\mathrm{Zn}$ anode cannot match well with the rapid ion adsorption/ desorption on the capacitive electrode, which limits the power density of $\mathrm{Zn}^{2+}$ AHSCs. To solve these issues, many studies focused on using the additives in electrolytes, adjusting the concentration of electrolytes, and designing sophisticated structure of composite anodes [172,173], as presented in Fig. 10. For instance, Wang et al. [173] designed the microporous $\mathrm{Zn}$ based MOF (ZIF)-derived anode (annealed at $500^{\circ} \mathrm{C}$ ), in which the trace amount of $\mathrm{Zn}^{0}$ provided nuclei for further $\mathrm{Zn}$ plating to achieve the dendrite-free deposition. The resulting $\mathrm{Zn}^{2+}$ AHSCs (AC//ZIF) exhibited ultralong cycling life and dendrite-free behavior for over 20,000 cycles. More recently, an effective strategy to accelerate the kinetics of $\mathrm{Zn}^{2+}$ transference and deposition was developed, in which the $\mathrm{Zn}$ anode was modified with a 3D nanoporous $\mathrm{ZnO}$ architecture [174]. Benefiting from the novel structure, the $\mathrm{Zn}$ plating kinetics was accelerated via the electrostatic attraction toward $\mathrm{Zn}^{2+}$ rather than the tightly and strongly hydrated one in the electrical double layer, and the $\mathrm{H}_{2}$ evolution was effectively prevented. Consequently, it achieved an average $\mathrm{Zn}$ utilization of $99.55 \%$. For the capacitive electrode, the capacity discrepancy with the battery-type electrode is the key challenge when assembling $\mathrm{Zn}^{2+}$ AHSCs. Therefore, considerable efforts have been devoted to introducing heteroatoms or functional groups into the materials, which are expected to provide pseudocapacitive contribution to promote the charge storage capability [175-178]. Furthermore, adjusting the desolvation degree of the solvated $\mathrm{Zn}$ ionic clusters can remarkably improve the capacitance of porous carbon materials. The smaller $[\mathrm{ZnCl}]^{+}\left(\mathrm{H}_{2} \mathrm{O}\right)_{n-1}$ clusters were demonstrated to be easier to access micropores in carbon electrodes [179]. Based on this mechanism, porous carbon//Zn AHSCs coupled with $\mathrm{ZnCl}_{2}$ WISE electrolyte delivered a high energy density of up to $217 \mathrm{~W} \mathrm{~h} \mathrm{~kg}^{-1}$ at a power density of $450 \mathrm{~W} \mathrm{~kg}^{-1}$ and an unprecedented cycling life of 100,000 cycles. As multivalent-ion AHSCs have only been defined in recent years, EDLC carbon materials have been mainly utilized as cathode, whereas pseudocapacitive materials have rarely been involved. In this regard, pseudocapacitive cathodes for multivalent-ion AHSCs are expected to be very promising in future studies (Fig. 10). A good recent demonstration used TiN as the pseudocapacitive cathode for $\mathrm{Zn}^{2+}$ AHSCs [42]. The effects of various anions $\left(\mathrm{SO}_{4}^{2-}, \mathrm{CH}_{3}{ }^{-}\right.$ $\mathrm{COO}^{-}$, and $\mathrm{Cl}^{-}$) in the electrolyte on TiN were carefully investigated by using DFT calculation. It was revealed that $\mathrm{SO}_{4}{ }^{2-}$ anions exhibited the lowest adsorption energy and could easily form the stable structure of $\mathrm{TiN}_{-} \mathrm{SO}_{4}$ after the adsorption process, thus enabling the participation of $\mathrm{SO}_{4}{ }^{2-}$ in the electrochemical process and promoting a two-step adsorption and intercalation energy storage mechanism. Owing to the outstanding electronic conductivity of TiN and the introduction of $\mathrm{SO}_{4}{ }^{2-}$ anions into the electrochemical process, the assembled $1.9 \mathrm{~V} \mathrm{TiN} / / \mathrm{Zn}$ AHSC exhibited a quite high capacitance of $489.8 \mathrm{~F} \mathrm{~g}^{-1}$ at a current density of $0.2 \mathrm{~A} \mathrm{~g}^{-1}$ and a capacitance of $314.5 \mathrm{~F} \mathrm{~g}^{-1}$ at a high current density of $1 \mathrm{~A} \mathrm{~g}^{-1}$ after 10,000 cycles. For electrolyte, rational design of the components and structure can further improve the electrochemical performance of $\mathrm{Zn}^{2+}$ AHSCs, such as stability and voltage window (Fig. 10). For example, using WISE containing $21 \mathrm{~m}$ LiTFSI and $1 \mathrm{~m} \mathrm{Zn}\left(\mathrm{CF}_{3^{-}}\right.$ $\left.\mathrm{SO}_{3}\right)_{2}$ as electrolyte could not only broaden the operating voltage of $\mathrm{Zn}^{2+}$ AHSC to $2.2 \mathrm{~V}$, but also enable high capacitance of

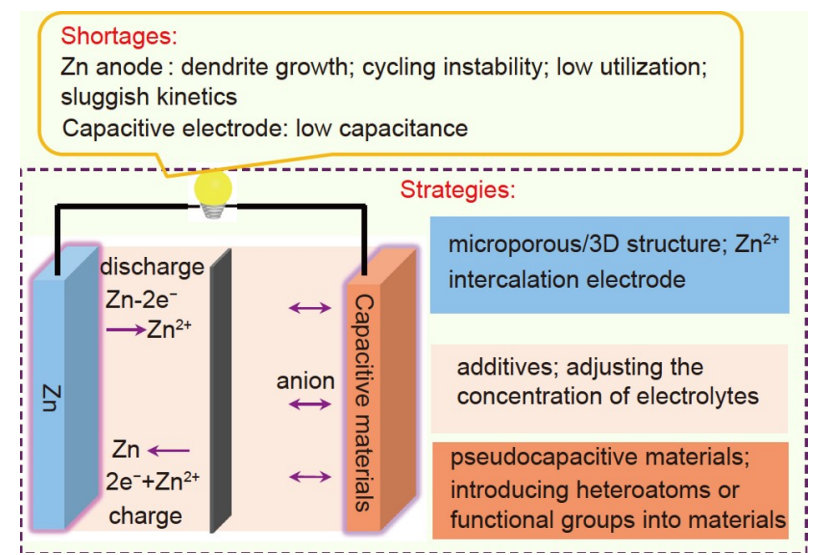

Figure 10 Summary of general shortages of $\mathrm{Zn}^{2+}$ AHSCs based on $\mathrm{Zn}$ anode and the corresponding solutions.

$214.3 \mathrm{~F} \mathrm{~g}^{-1}$ after 5,000 cycles [180]. Therefore, to completely avoid the dendrite issue at the anode side, constructing multivalent-ion AHSCs based on capacitive anode and ion-insertion/ intercalation battery-type cathode will also be quite interesting [181-183].

\section{CONCLUSION AND OUTLOOK}

AHSCs represent an important future direction for the nextgeneration electrical energy storage, which are expected to provide higher energy density than aqueous SCs and higher power density than aqueous batteries. In this review, recent advances in the optimization of the battery-type electrodes, the capacitive electrodes, and the electrolytes of AHSCs are summarized (Table 1). The ingenious design of some emerging AHSC devices with unique configurations and charge storage process are also presented. Despite the significant progress made in this field, it remains a huge challenge to attain high comprehensive performance of AHSCs for practical applications. Therefore, approaches to simultaneously achieve high energy density, high power density, as well as long cycling stability of AHSCs still need to be investigated. The underlying reasons for the restriction of current device performance are strongly related to the relatively sluggish kinetics and larger structural variation of battery-type electrode and the capacitance limitation of the capacitive electrode, which result in the mismatch of the two electrodes in kinetics and charge storage ability. Noteworthily, substantial improvements in energy and power densities are the prerequisite for improving the competitiveness of AHSCs compared with other aqueous energy storage devices. To address these challenges, more efforts should be devoted to the following aspects.

(1) For the battery-type electrode, the development of unique $3 \mathrm{D}$ electrodes is still required. It is well-known that $3 \mathrm{D}$ electrodes can principally provide sufficient ion diffusion channels and continuous electron transport pathways, which are ideal electrode architectures to ensure simultaneous ion/electron transportation for synergistically boosting the rate capability of battery-type electrode. Moreover, 3D structure also makes the conformal modification of the electrode with other materials much easier, which is crucial to substantially improve the electrode cycling stability. However, the mass loading of current 3D battery electrodes in AHSCs is still very low. For practical 
Table 1 Summary of the electrochemical performance of typical AHSCs

\begin{tabular}{|c|c|c|c|c|c|c|}
\hline Device/electrode & Electrolyte & Performance & $\begin{array}{c}\text { Energy } \\
\text { density }\end{array}$ & $\begin{array}{c}\text { Power } \\
\text { density }\end{array}$ & Voltage & Ref. \\
\hline \multicolumn{7}{|c|}{ Design of battery-type electrode } \\
\hline $\mathrm{Ni}_{0.25} \mathrm{Mn}_{0.75} \mathrm{O} @ \mathrm{C} / / \mathrm{AC}$ & Aqueous PVA-LiCl & $95.5 \%, 5200$ cycles, $12 \mathrm{~mA} \mathrm{~cm}^{-2}$ & $4.72 \mathrm{~mW} \mathrm{~h} \mathrm{~cm}^{-3}$ & $776 \mathrm{~mW} \mathrm{~cm}^{-3}$ & $0-2.4 \mathrm{~V}$ & [55] \\
\hline $\mathrm{Na}_{4} \mathrm{Mn}_{9} \mathrm{O}_{18} / / \mathrm{AC}$ & Aqueous $\mathrm{Na}_{2} \mathrm{SO}_{4}$ & $\sim 100 \%, 1000$ cycles, $4 \mathrm{C}$ & - & - & $0.4-1.8 \mathrm{~V}$ & {$[56]$} \\
\hline $\mathrm{K}_{0.45} \mathrm{MnO}_{2} \cdot 0.3 \mathrm{H}_{2} \mathrm{O} / / \mathrm{AC}$ & Aqueous $\mathrm{K}_{2} \mathrm{SO}_{4}$ & - & $43.1 \mathrm{~W} \mathrm{~h} \mathrm{~kg}^{-1}$ & $2500 \mathrm{~W} \mathrm{~kg}^{-1}$ & $0-1.65 \mathrm{~V}$ & {$[58]$} \\
\hline $\mathrm{K}_{2} \mathrm{Fe}^{\mathrm{II}}\left[\mathrm{Fe}^{\mathrm{II}}(\mathrm{CN})_{6}\right] 2 \mathrm{H}_{2} \mathrm{O}$ & Aqueous $\mathrm{K}_{2} \mathrm{SO}_{4}$ & $>85 \%, 500$ cycles, $21.4 \mathrm{C}$ & - & - & $0-1.2 \mathrm{~V}$ & {$[78]$} \\
\hline $\mathrm{AC} / / \mathrm{NaTi}_{2}\left(\mathrm{PO}_{4}\right)_{3}$ & PVA- $\mathrm{NaClO}_{4}$ & $79.2 \%, 10,000$ cycles & $5.8 \mathrm{~mW} \mathrm{~h} \mathrm{~cm}^{-3}$ & $999 \mathrm{~mW} \mathrm{~cm}^{-3}$ & $0-2.4 \mathrm{~V}$ & {$[75]$} \\
\hline $\mathrm{AC} / / \mathrm{Bi}_{2} \mathrm{O}_{3} @ \mathrm{C}$ & Aqueous $\mathrm{Na}_{2} \mathrm{SO}_{4}-\mathrm{NaCl}$ & $72.3 \%, 650$ cycles, $2 \mathrm{~A} \mathrm{~g}^{-1}$ & $18.94 \mathrm{~W} \mathrm{~h} \mathrm{~kg}^{-1}$ & $1267 \mathrm{~W} \mathrm{~kg}^{-1}$ & $0-1.9 \mathrm{~V}$ & {$[107]$} \\
\hline $\begin{array}{l}\text { ZnNiCo-P//reduced } \\
\text { graphene oxides }\end{array}$ & Aqueous $\mathrm{KOH}$ & $89 \%, 8000$ cycles, $10 \mathrm{Ag} \mathrm{g}^{-1}$ & $60.1 \mathrm{~W} \mathrm{~h} \mathrm{~kg}^{-1}$ & $19.54 \mathrm{~kW} \mathrm{~kg}^{-1}$ & $0-1.6 \mathrm{~V}$ & [39] \\
\hline $\mathrm{KNiPO}_{4} / / \mathrm{AC}$ & Aqueous $\mathrm{KOH}$ & $93 \%, 2000$ cycles, $1 \mathrm{~mA} \mathrm{~cm}^{-2}$ & $13 \mathrm{~W} \mathrm{~h} \mathrm{~kg}^{-1}$ & $900 \mathrm{~W} \mathrm{~kg}^{-1}$ & $0-1.5 \mathrm{~V}$ & [41] \\
\hline $\begin{array}{c}\left(\mathrm{NH}_{4}\right)(\mathrm{Ni}, \mathrm{Co}) \mathrm{PO}_{4} \cdot 0.67 \mathrm{H}_{2} \mathrm{O} / / \text { porous } \\
\text { carbon }\end{array}$ & Aqueous $\mathrm{KOH}$ & $77.5 \%, 7000$ cycles, $1 \mathrm{Ag}^{-1}$ & $44.5 \mathrm{~W} \mathrm{~h} \mathrm{~kg}^{-1}$ & $7.4 \mathrm{~kW} \mathrm{~kg}^{-1}$ & $0-1.55 \mathrm{~V}$ & [73] \\
\hline$(\mathrm{Cu}, \mathrm{Ni}) \mathrm{O} / / \mathrm{AC}$ & Aqueous $\mathrm{NaOH}$ & $100.9 \%, 6000$ cycles, $5 \mathrm{~mA} \mathrm{~cm}^{-2}$ & $50.3 \mathrm{~W} \mathrm{~h} \mathrm{~kg}^{-1}$ & $5213.4 \mathrm{~W} \mathrm{~kg}^{-1}$ & $0-1.8 \mathrm{~V}$ & [87] \\
\hline $\mathrm{Ni}-\mathrm{Co}-\mathrm{S} / \mathrm{G} / / \mathrm{PCNS}$ & Aqueous $\mathrm{KOH}$ & $85 \%, 10,000$ cycles, $10 \mathrm{Ag}^{-1}$ & $43.3 \mathrm{~W} \mathrm{~h} \mathrm{~kg}^{-1}$ & $22.1 \mathrm{~kW} \mathrm{~kg}^{-1}$ & $0-1.6 \mathrm{~V}$ & [84] \\
\hline Cabon $/ \mathrm{PbO}_{2} / / \mathrm{AC}$ & $\mathrm{CH}_{3} \mathrm{SO}_{3} \mathrm{H}+\mathrm{Pb}\left(\mathrm{NO}_{3}\right)_{2}+\mathrm{NaNO}_{3}$ & $100 \%, 5000$ cycles, $10 \mathrm{~mA} \mathrm{~cm}^{-2}$ & $29 \mathrm{~W} \mathrm{~h} \mathrm{~kg}^{-1}$ & - & $0-2.1 \mathrm{~V}$ & {$[112]$} \\
\hline $\mathrm{SiO}_{2} / \mathrm{PbO}_{2} / / \mathrm{AC}$ & Aqueous $\mathrm{H}_{2} \mathrm{SO}_{4}$ & $91 \%, 1000$ cycles, $3 \mathrm{Ag}^{-1}$ & $61 \mathrm{Wh} \mathrm{kg}^{-1}$ & - & $0-2.4 \mathrm{~V}$ & {$[115]$} \\
\hline $3 \mathrm{~d}-\mathrm{Ti} / \mathrm{PbO}_{2} / / \mathrm{AC}$ & Aqueous $\mathrm{H}_{2} \mathrm{SO}_{4}$ & $99.2 \%, 1000$ cycles, $5 \mathrm{~mA} \mathrm{~cm}^{-2}$ & $49.4 \mathrm{~W} \mathrm{~h} \mathrm{~kg}^{-1}$ & - & $0-2.3 \mathrm{~V}$ & [116] \\
\hline \multicolumn{7}{|c|}{ Design of capacitive electrode } \\
\hline$n-\mathrm{Ti}_{2} \mathrm{CT}_{x} / \mathrm{C} / / \mathrm{Zn}$ & $\mathrm{LiTFSI}+\mathrm{Zn}\left(\mathrm{CF}_{3} \mathrm{SO}_{3}\right)_{2} \mathrm{WIS}$ & $96 \%, 12,500$ cycles, $0.5 \mathrm{~A} \mathrm{~g}^{-1}$ & - & - & $0-2 \mathrm{~V}$ & {$[43]$} \\
\hline $\mathrm{NiO} / \mathrm{rGO} / / \mathrm{PANI}_{2.5}$ & Aqueous $\mathrm{KOH}$ & $\sim 100 \%, 100,000$ cycles, $5 \mathrm{Ag}^{-1}$ & $81 \mathrm{Wh} \mathrm{kg}^{-1}$ & $13,794 \mathrm{~W} \mathrm{~kg}^{-1}$ & $0-1.6 \mathrm{~V}$ & {$[44]$} \\
\hline \multicolumn{7}{|c|}{ Design of electrolytes } \\
\hline $\mathrm{Zn} / / \mathrm{AC}$ & Water/ethyleneglycol- $\mathrm{ZnSO}_{4}$ & $80 \%, 5000$ cycles, $10 \mathrm{~A} \mathrm{~g}^{-1}$ & $56.44 \mathrm{~W} \mathrm{~h} \mathrm{~kg}^{-1}$ & $8153 \mathrm{~W} \mathrm{~kg}^{-1}$ & $0-1.6 \mathrm{~V}$ & {$[36]$} \\
\hline $\mathrm{CNTs} / / \mathrm{Fe}_{3} \mathrm{O}_{4}-\mathrm{C}$ & PVA-KOH & $67.7 \%, 1000$ cycles, $5.5 \mathrm{~mA} \mathrm{~cm}^{-2}$ & $1.56 \mathrm{~mW} \mathrm{~h} \mathrm{~cm}^{-3}$ & $0.48 \mathrm{~W} \mathrm{~cm}^{-3}$ & $0-1.6 \mathrm{~V}$ & {$[105]$} \\
\hline $\mathrm{PCMS} / / \mathrm{PNTCDA}$ & $\mathrm{NaClO}_{4}$ WIS & $86 \%, 1000$ cycles, $1 \mathrm{Ag}^{-1}$ & $65.1 \mathrm{Wh} \mathrm{kg}^{-1}$ & $20 \mathrm{~kW} \mathrm{~kg}^{-1}$ & $0-2 \mathrm{~V}$ & [159] \\
\hline $\mathrm{AC} / / \mathrm{Nb}_{2} \mathrm{O}_{5}$ & LiTFSI/(EMIM-TFSI) 2.0 WIS & $84 \%, 3000$ cycles, $1 \mathrm{~A} \mathrm{~g}^{-1}$ & $51.9 \mathrm{~W} \mathrm{~h} \mathrm{~kg}^{-1}$ & $4.9 \mathrm{~kW} \mathrm{~kg}^{-1}$ & $0.8-2.8 \mathrm{~V}$ & {$[161]$} \\
\hline $\mathrm{LiMn}_{2} \mathrm{O}_{4} / / \mathrm{AC}$ & $\mathrm{CH}_{3} \mathrm{COOLi} / \mathrm{K}$ WIS & $100 \%, 20,000$ cycles, $10 \mathrm{Ag}^{-1}$ & $58 \mathrm{~W} \mathrm{~h} \mathrm{~kg}^{-1}$ & $6000 \mathrm{~W} \mathrm{~kg}^{-1}$ & $0-2 \mathrm{~V}$ & [165] \\
\hline \multicolumn{7}{|c|}{ The advanced new-type AHSCs } \\
\hline $\mathrm{AC} / / \mathrm{Zn}$ & $\mathrm{Zn}\left(\mathrm{CF}_{3} \mathrm{SO}_{3}\right)_{2}$-acetonitrile & $91 \%, 20,000$ cycles, $1 \mathrm{~A} \mathrm{~g}^{-1}$ & $52.7 \mathrm{~W} \mathrm{~h} \mathrm{~kg}^{-1}$ & - & $0-1.8 \mathrm{~V}$ & {$[2]$} \\
\hline $\mathrm{TiN} / / \mathrm{Zn}$ & ${\mathrm{PAM}-\mathrm{ZnSO}_{4}}_{4}$ & $\sim 84 \%, 3500$ cycles, $0.5 \mathrm{Ag}^{-1}$ & - & - & $0.1-1.9 \mathrm{~V}$ & {$[42]$} \\
\hline $\mathrm{V}_{2} \mathrm{O}_{3} @ \mathrm{C} / / \mathrm{V}_{2} \mathrm{O}_{3} @ \mathrm{C}$ & PVA-LiCl & $93 \%, 6000$ cycles, $2 \mathrm{~mA} \mathrm{~cm}^{-2}$ & $15.9 \mathrm{~mW} \mathrm{~h} \mathrm{~cm}^{-3}$ & $6800 \mathrm{~mW} \mathrm{~cm}^{-3}$ & $0-2 \mathrm{~V}$ & {$[152]$} \\
\hline $\mathrm{NiCo}_{2} \mathrm{O}_{4} / / \mathrm{MoO}_{2}-\mathrm{C}$ & Aqueous $\mathrm{LiOH}$ & $130 \%, 3000$ cycles, $10 \mathrm{~mA} \mathrm{~cm}^{-2}$ & $41.8 \mathrm{~W} \mathrm{~h} \mathrm{~kg}^{-1}$ & $19.922 \mathrm{~kW} \mathrm{~kg}^{-1}$ & $0-1.8 \mathrm{~V}$ & {$[166]$} \\
\hline Ni@CNT//Ni@CNT & PVA-KOH & $100 \%, 10,000$ cycles, $50 \mathrm{~mA} \mathrm{~cm}^{-2}$ & $1.39 \mathrm{~mW} \mathrm{~h} \mathrm{~cm}^{-3}$ & $440 \mathrm{~mW} \mathrm{~cm}^{-3}$ & $0-1.8 \mathrm{~V}$ & {$[167]$} \\
\hline $\mathrm{MnO}_{2} / / \mathrm{AC}$ & Aqueous $\mathrm{Zn}\left(\mathrm{CF}_{3} \mathrm{SO}_{3}\right)_{2}$ & $93.4 \%, 5000$ cycles, - & $29.5 \mathrm{~W} \mathrm{~h} \mathrm{~kg}^{-1}$ & - & $0-2 \mathrm{~V}$ & [169] \\
\hline AC//ZIF & Aqueous $\mathrm{ZnSO}_{4}$ & $72 \%, 20,000$ cycles, $4 \mathrm{~A} \mathrm{~g}^{-1}$ & $140.8 \mathrm{~W} \mathrm{~h} \mathrm{~kg}^{-1}$ & $2850 \mathrm{~W} \mathrm{~kg}^{-1}$ & $0.2-1.8 \mathrm{~V}$ & {$[173]$} \\
\hline Porous carbon//Zn & $\mathrm{ZnCl}_{2}$ WIS & $95.1 \%, 100,000$ cycles, $5 \mathrm{~A} \mathrm{~g}^{-1}$ & $\begin{array}{l}217 \mathrm{~W} \mathrm{~h} \mathrm{~kg}^{-1} \text { (based on } \\
\text { carbon materials) }\end{array}$ & - & $0-1.8 \mathrm{~V}$ & [179] \\
\hline Phosphorene//Zn & $\mathrm{ZnCl}_{2}-\mathrm{Et}_{4} \mathrm{NBF}_{4} / \mathrm{PC}$ & $33 \%, 90,000$ cycles, $0.5 \mathrm{Ag}^{-1}$ & $\begin{array}{l}315.6 \mathrm{Wh} \mathrm{kg}^{-1} \text { (based } \\
\text { on the phosphorene) }\end{array}$ & $23,582.4 \mathrm{~W} \mathrm{~kg}^{-1}$ & $0-2.5 \mathrm{~V}$ & {$[180]$} \\
\hline $\mathrm{AC} / / \mathrm{Zn}$ & Aqueous $\mathrm{ZnSO}_{4}$ & $91 \%, 10,000$ cycles, $1 \mathrm{Ag}^{-1}$ & $84 \mathrm{~W} \mathrm{~h} \mathrm{~kg}^{-1}$ & $14.9 \mathrm{~kW} \mathrm{~kg}^{-1}$ & $0.2-1.8 \mathrm{~V}$ & {$[183]$} \\
\hline
\end{tabular}


application, it is very important to discover novel synthesis or processing methods to increase the mass loading while maintaining the benefits of $3 \mathrm{D}$ architecture.

(2) For capacitive electrode, the future material selection and micro-nanostructure design should further focus on new pseudocapacitive materials, in particular, high-conductivity MOFs, conductive 2D MXenes, and "intercalation pseudocapacitive oxides" such as $\mathrm{MoO}_{x}, \mathrm{Nb}_{2} \mathrm{O}_{5}$. These promising materials can exhibit higher capacitance than traditional EDLC materials, in particular, when normalized to volume. It is therefore more convenient to achieve the charge balance with the battery-type electrode when assembling AHSCs devices. In order to design multivalent ion AHSCs using pseudocapacitive materials, it is necessary to systematically investigate the charge storage process and kinetics of these materials upon multivalent ion insertion. Theoretical calculation, computing modeling, and in situ or ex situ probing of the evolution of the crystal/electronic structure, phase, and micro-nanostructure are of extreme significance to unveil the charge storage mechanism and distinguish it from diffusion-controlled Faradaic reactions.

(3) Electrolyte is another key parameter in AHSCs, which is not only strongly related to the energy and power densities of the devices, but also determinative of the stability of the electrodes and device. Introduction of unique electrolytes with wide electrochemical stability window such as WISE, molecular crowding electrolyte, and hydrate-melt electrolyte, into AHSCs is the most promising strategy to increase the energy density of AHSCs. In this context, however, in-depth understating of the ion transport mechanism and improvement in the ionic conductivity of these electrolytes are urgent to ensure the high power density of AHSCs. For the more comprehensive understanding of the electrochemical stability window and widened mechanism, and for promoting the interfacial charge transfer, interfacial phase at the two electrode sides should be carefully monitored and analyzed when using these electrolytes. Solvation structure is another important factor that determines the charge transfer of ions at the interface, as it significantly influences the interphase component and desolvation kinetics. Thus the design of optimized solvation structure of electrolytes is also of great importance in the future.

(4) With the increasing demand of energy storage devices in future smart society, consideration of the use effectiveness under different environments is urgent and highly desirable. The AHSCs using (quasi-)solid-state electrolytes will be the trend due to their safety and good mechanical robustness. However, we have to acknowledge the problem that the interfacial contact of solid electrolytes with electrode materials is generally limited in traditional sandwiched device architectures, which is not good for rapid charging/discharging of AHSCs. Integrated device architecture with (quasi-)solid-state electrolyte infiltrated into $3 \mathrm{D}$ electrode is of promising potential to address the above challenge. To this end, novel strategies toward the 3D integration need to be explored in future studies. More attention should also be paid to the interface engineering of electrode/electrolyte under bending, twisting, high/low temperature, external stress, and other real environments. Comprehensive understanding and complete solution of these issues are crucial to promote the design of multifunctional AHSCs for practical applications.

(5) Multivalent ion AHSCs using charge carriers of $\mathrm{Zn}^{2+}, \mathrm{Ca}^{2+}$, $\mathrm{Mg}^{2+}, \mathrm{Al}^{3+}$, etc. are very promising to deliver both high energy density and power density. However, this type of device is still at the infant stage, and realizing high comprehensive performance of multivalent ion AHSCs is still quite a challenging task. For multivalent ion AHSCs using corresponding metal as the anode and capacitive materials as the cathode, the dendrite issue or/and sluggish plating/stripping kinetics of anode are the main obstacles to achieve high rate performance and power density. When capacitive anode is used for assembling multivalent ion AHSCs, the challenge is on the cathode side where multivalent metal ions should reversibly insert into/deinsert from batterytype electrode materials. Currently, such host materials are still lacking; in particular, the multivalent ion uptake generally leads to serious structural damage to the host materials due to the strong interactions with crystal lattice. Tremendous efforts should be devoted to stabilizing the host materials, while not deteriorating the ion diffusion ability.

Received 29 March 2021; accepted 8 June 2021; published online 16 August 2021

1 Goodenough JB. How we made the Li-ion rechargeable battery. Nat Electron, 2018, 1: 204

2 Jia R, Shen G, Chen D. Recent progress and future prospects of sodium-ion capacitors. Sci China Mater, 2020, 63: 185-206

3 Goodenough JB, Kim Y. Challenges for rechargeable Li batteries. Chem Mater, 2010, 22: 587-603

$4 \mathrm{Li} \mathrm{M}, \mathrm{Lu}$ J, Chen Z, et al. 30 years of lithium-ion batteries. Adv Mater, 2018, 30: 1800561

5 Kang B, Ceder G. Battery materials for ultrafast charging and discharging. Nature, 2009, 458: 190-193

6 Shu C, Wang J, Long J, et al. Understanding the reaction chemistry during charging in aprotic lithium-oxygen batteries: Existing problems and solutions. Adv Mater, 2019, 31: 1804587

7 Dubal DP, Chodankar NR, Kim DH, et al. Towards flexible solid-state supercapacitors for smart and wearable electronics. Chem Soc Rev, 2018, 47: 2065-2129

8 Shi X, Wu ZS, Bao X. Recent advancements and perspective of highperformance printed power sources with multiple form factors. Electrochem Energ Rev, 2020, 3: 581-612

9 Das P, Shi X, Fu Q, et al. Substrate-free and shapeless planar microsupercapacitors. Adv Funct Mater, 2020, 30: 1908758

10 Chao D, Qiao SZ. Toward high-voltage aqueous batteries: Super- or low-concentrated electrolyte? Joule, 2020, 4: 1846-1851

11 Pramudita JC, Sehrawat D, Goonetilleke D, et al. An initial review of the status of electrode materials for potassium-ion batteries. Adv Energy Mater, 2017, 7: 1602911

12 Dhir S, Wheeler S, Capone I, et al. Outlook on K-ion batteries. Chem, 2020, 6: $2442-2460$

13 Zhao C, Lu Y, Chen L, et al. Flexible Na batteries. InfoMat, 2019, 2: $126-138$

14 Bin D, Wang F, Tamirat AG, et al. Progress in aqueous rechargeable sodium-ion batteries. Adv Energy Mater, 2018, 8: 1703008

15 Zheng S, Huang H, Dong Y, et al. Ionogel-based sodium ion microbatteries with a $3 \mathrm{D}$ Na-ion diffusion mechanism enable ultrahigh rate capability. Energy Environ Sci, 2020, 13: 821-829

16 Raza W, Ali F, Raza N, et al. Recent advancements in supercapacitor technology. Nano Energy, 2018, 52: 441-473

17 Zhang LL, Zhao XS. Carbon-based materials as supercapacitor electrodes. Chem Soc Rev, 2009, 38: 2520-2531

18 Shao Y, El-Kady MF, Sun J, et al. Design and mechanisms of asymmetric supercapacitors. Chem Rev, 2018, 118: 9233-9280

19 Simon P, Gogotsi Y. Materials for electrochemical capacitors. Nat Mater, 2008, 7: 845-854

20 Lee HY, Goodenough JB. Supercapacitor behavior with $\mathrm{KCl}$ electrolyte. J Solid State Chem, 1999, 144: 220-223

21 Augustyn V, Come J, Lowe MA, et al. High-rate electrochemical energy storage through $\mathrm{Li}^{+}$intercalation pseudocapacitance. Nat Mater, 
2013, 12: 518-522

22 Naoi K, Ishimoto S, Miyamoto J, et al. Second generation 'nanohybrid supercapacitor': Evolution of capacitive energy storage devices. Energy Environ Sci, 2012, 5: 9363-9373

23 Anasori B, Lukatskaya MR, Gogotsi Y. 2D metal carbides and nitrides (MXenes) for energy storage. Nat Rev Mater, 2017, 2: 16098-16114

24 Dubal DP, Ayyad O, Ruiz V, et al. Hybrid energy storage: The merging of battery and supercapacitor chemistries. Chem Soc Rev, 2015, 44: $1777-1790$

25 Simon P, Gogotsi Y. Perspectives for electrochemical capacitors and related devices. Nat Mater, 2020, 19: 1151-1163

26 Zuo W, Li R, Zhou C, et al. Battery-supercapacitor hybrid devices: Recent progress and future prospects. Adv Sci, 2017, 4: 1600539

27 Chang Z, Yang Y, Li M, et al. Green energy storage chemistries based on neutral aqueous electrolytes. J Mater Chem A, 2014, 2: 10739 10755

28 Lukatskaya MR, Dunn B, Gogotsi Y. Multidimensional materials and device architectures for future hybrid energy storage. Nat Commun, 2016, 7: 12647-12659

29 Ding J, Hu W, Paek E, et al. Review of hybrid ion capacitors: From aqueous to lithium to sodium. Chem Rev, 2018, 118: 6457-6498

30 Zhao X, Zhang Y, Wang Y, et al. Battery-type electrode materials for sodium-ion capacitors. Batteries Supercaps, 2019, 2: 899-917

31 Kühnel RS, Reber D, Battaglia C. A high-voltage aqueous electrolyte for sodium-ion batteries. ACS Energy Lett, 2017, 2: 2005-2006

32 Pell WG, Conway BE. Peculiarities and requirements of asymmetric capacitor devices based on combination of capacitor and battery-type electrodes. J Power Sources, 2004, 136: 334-345

33 Yu L, Chen GZ. Supercapatteries as high-performance electrochemical energy storage devices. Electrochem Energ Rev, 2020, 3: 271-285

34 Liu W, Li L, Gui Q, et al. Novel hybrid supercapacitors based on nanoarray electrodes. Acta Physico-Chim Sin, 2020, 36: 1904049

35 Liang Y, Dong H, Aurbach D, et al. Current status and future directions of multivalent metal-ion batteries. Nat Energy, 2020, 5: 646-656

36 Li F, Yu L, Hu Q, et al. Fabricating low-temperature-tolerant and durable Zn-ion capacitors via modulation of co-solvent molecular interaction and cation solvation. Sci China Mater, 2021, 64: 1609-1620

37 Cottineau T, Toupin M, Delahaye T, et al. Nanostructured transition metal oxides for aqueous hybrid electrochemical supercapacitors. Appl Phys A, 2005, 82: 599-606

38 Wang Y, Guo J, Wang T, et al. Mesoporous transition metal oxides for supercapacitors. Nanomaterials, 2015, 5: 1667-1689

39 Li J, Liu Z, Zhang Q, et al. Anion and cation substitution in transitionmetal oxides nanosheets for high-performance hybrid supercapacitors. Nano Energy, 2019, 57: 22-33

40 Shi B, Shang Y, Pei Y, et al. Low tortuous, highly conductive, and high-areal-capacity battery electrodes enabled by through-thickness aligned carbon fiber framework. Nano Lett, 2020, 20: 5504-5512

41 Priyadharsini N, Kalai Selvan R. Nano-sheet-like $\mathrm{KNiPO}_{4}$ as a positive electrode material for aqueous hybrid supercapacitors. Electrochim Acta, 2017, 246: 963-970

42 Huang Z, Wang $\mathrm{T}$, Song $\mathrm{H}$, et al. Effects of anion carriers on capacitance and self-discharge behaviors of zinc ion capacitors. Angew Chem Int Ed, 2021, 60: 1011-1021

43 Li X, Li M, Yang Q, et al. Vertically aligned $\mathrm{Sn}^{4+}$ preintercalated $\mathrm{Ti}_{2} \mathrm{CT}_{X}$ MXene sphere with enhanced $\mathrm{Zn}$ ion transportation and superior cycle lifespan. Adv Energy Mater, 2020, 10: 2001394

44 Ock IW, Choi JW, Jeong HM, et al. Synthesis of pseudocapacitive polymer chain anode and subnanoscale metal oxide cathode for aqueous hybrid capacitors enabling high energy and power densities along with long cycle life. Adv Energy Mater, 2018, 8: 1702895

45 Luan $\mathrm{Y}$, Zhang $\mathrm{H}$, Yang $\mathrm{F}$, et al. Rational design of $\mathrm{NiCo}_{2} \mathrm{~S}_{4}$ nanoparticles@N-doped CNT for hybrid supercapacitor. Appl Surf Sci, 2018, 447: 165-172

46 Liu R, Ma L, Niu G, et al. Oxygen-deficient bismuth oxide/graphene of ultrahigh capacitance as advanced flexible anode for asymmetric supercapacitors. Adv Funct Mater, 2017, 27: 1701635

47 Yi H, Wang H, Jing Y, et al. Asymmetric supercapacitors based on carbon nanotubes@NiO ultrathin nanosheets core-shell composites and MOF-derived porous carbon polyhedrons with super-long cycle life. J Power Sources, 2015, 285: 281-290

48 Yu N, Yin H, Zhang W, et al. High-performance fiber-shaped allsolid-state asymmetric supercapacitors based on ultrathin $\mathrm{MnO}_{2}$ nanosheet/carbon fiber cathodes for wearable electronics. Adv Energy Mater, 2016, 6: 1501458

49 Tan J, Liu J. Electrolyte engineering toward high-voltage aqueous energy storage devices. Energy Environ Mater, 2020, eem2.12125

50 Guo Y, Bae J, Fang Z, et al. Hydrogels and hydrogel-derived materials for energy and water sustainability. Chem Rev, 2020, 120: 7642-7707

51 Yu C, An J, Chen Q, et al. Recent advances in design of flexible electrodes for miniaturized supercapacitors. Small Methods, 2020, 4 1900824

52 Hou BH, Wang YY, Ning QL, et al. Self-supporting, flexible, additivefree, and scalable hard carbon paper self-interwoven by $1 \mathrm{D}$ microbelts: Superb room/low-temperature sodium storage and working mechanism. Adv Mater, 2019, 31: 1903125

53 Yun TG, Park M, Kim DH, et al. All-transparent stretchable electrochromic supercapacitor wearable patch device. ACS Nano, 2019, 13: 3141-3150

54 Wang FX, Xiao SY, Zhu YS, et al. Spinel $\mathrm{LiMn}_{2} \mathrm{O}_{4}$ nanohybrid as high capacitance positive electrode material for supercapacitors. J Power Sources, 2014, 246: 19-23

55 Zuo W, Xie C, Xu P, et al. A novel phase-transformation activation process toward Ni-Mn-O nanoprism arrays for $2.4 \mathrm{~V}$ ultrahighvoltage aqueous supercapacitors. Adv Mater, 2017, 29: 1703463

56 Whitacre JF, Tevar A, Sharma S. $\mathrm{Na}_{4} \mathrm{Mn}_{9} \mathrm{O}_{18}$ as a positive electrode material for an aqueous electrolyte sodium-ion energy storage device. Electrochem Commun, 2010, 12: 463-466

57 Qu Q, Li L, Tian S, et al. A cheap asymmetric supercapacitor with high energy at high power: Activated carbon $/ / \mathrm{K}_{0.27} \mathrm{MnO}_{2} \cdot 0.6 \mathrm{H}_{2} \mathrm{O}$. J Power Sources, 2010, 195: 2789-2794

58 Zhang $\mathrm{BH}$, Liu $\mathrm{Y}$, Chang $\mathrm{Z}$, et al. Nanowire $\mathrm{K}_{0.19} \mathrm{MnO}_{2}$ from hydrothermal method as cathode material for aqueous supercapacitors of high energy density. Electrochim Acta, 2014, 130: 693-698

59 Qin C, Li Y, Lv S, et al. Enhancing electrochemical performance of $\mathrm{LiFePO}_{4}$ by vacuum-infiltration into expanded graphite for aqueous Li-ion capacitors. Electrochim Acta, 2017, 253: 413-421

60 Wang $\mathrm{H}$, Zhang $\mathrm{T}$, Chen $\mathrm{C}$, et al. High-performance aqueous symmetric sodium-ion battery using NASICON-structured $\mathrm{Na}_{2} \mathrm{VTi}\left(\mathrm{PO}_{4}\right)_{3}$. Nano Res, 2017, 11: 490-498

61 Wu X, Cao Y, Ai X, et al. A low-cost and environmentally benign aqueous rechargeable sodium-ion battery based on $\mathrm{NaTi}_{2}\left(\mathrm{PO}_{4}\right)_{3}-$ $\mathrm{Na}_{2} \mathrm{NiFe}(\mathrm{CN})_{6}$ intercalation chemistry. Electrochem Commun, 2013, 31: $145-148$

62 Jiang L, Lu Y, Zhao C, et al. Building aqueous K-ion batteries for energy storage. Nat Energy, 2019, 4: 495-503

63 Yu F, Zhang S, Fang C, et al. Electrochemical characterization of P2type layered $\mathrm{Na}_{2 / 3} \mathrm{Ni}_{1 / 4} \mathrm{Mn}_{3 / 4} \mathrm{O}_{2}$ cathode in aqueous hybrid sodium/ lithium ion electrolyte. Ceramics Int, 2017, 43: 9960-9967

64 Ruffo R, Wessells C, Huggins RA, et al. Electrochemical behavior of $\mathrm{LiCoO}_{2}$ as aqueous lithium-ion battery electrodes. Electrochem Commun, 2009, 11: 247-249

65 Luo JY, Xia YY. Aqueous lithium-ion battery $\mathrm{LiTi}_{2}\left(\mathrm{PO}_{4}\right)_{3} / \mathrm{LiMn}_{2} \mathrm{O}_{4}$ with high power and energy densities as well as superior cycling stability. Adv Funct Mater, 2007, 17: 3877-3884

66 Yang Q, Cui S, Ge Y, et al. Porous single-crystal $\mathrm{NaTi}_{2}\left(\mathrm{PO}_{4}\right)_{3}$ via liquid transformation of $\mathrm{TiO}_{2}$ nanosheets for flexible aqueous Na-ion capacitor. Nano Energy, 2018, 50: 623-631

67 Deng W, Shen Y, Qian J, et al. A polyimide anode with high capacity and superior cyclability for aqueous $\mathrm{Na}$-ion batteries. Chem Commun, 2015, 51: 5097-5099

68 Li L, Peng S, Wu HB, et al. A flexible quasi-solid-state asymmetric electrochemical capacitor based on hierarchical porous $\mathrm{V}_{2} \mathrm{O}_{5}$ nanosheets on carbon nanofibers. Adv Energy Mater, 2015, 5: 1500753

69 Deng $\mathrm{C}$, Zhang S, Dong Z, et al. 1D nanostructured sodium vanadium oxide as a novel anode material for aqueous sodium ion batteries. 
Nano Energy, 2014, 4: 49-55

70 Huang Y, Zeng Y, Yu M, et al. Recent smart methods for achieving high-energy asymmetric supercapacitors. Small Methods, 2018, 2: 1700230

71 Zhou C, Zhang Y, Li Y, et al. Construction of high-capacitance 3D CoO@polypyrrole nanowire array electrode for aqueous asymmetric supercapacitor. Nano Lett, 2013, 13: 2078-2085

72 Ramkumar B, Yuvaraj S, Surendran S, et al. Synthesis and characterization of carbon coated $\mathrm{LiCo}_{1 / 3} \mathrm{Ni}_{1 / 3} \mathrm{Mn}_{1 / 3} \mathrm{O}_{2}$ and bio-mass derived graphene like porous carbon electrodes for aqueous Li-ion hybrid supercapacitor. J Phys Chem Solids, 2018, 112: 270-279

73 Wang $\mathrm{M}$, Zhao $\mathrm{Y}$, Zhang $\mathrm{X}$, et al. Interface-rich core-shell ammonium nickel cobalt phosphate for high-performance aqueous hybrid energy storage device without a depressed power density. Electrochim Acta, 2018, 272: 184-191

74 Anisimov VI, Korotin MA, Kurmaev EZ. Band-structure description of Mott insulators (NiO, $\mathrm{MnO}, \mathrm{FeO}, \mathrm{CoO}$ ). J Phys-Condens Matter, 1990, 2: 3973-3987

75 Tan J, Zhu W, Gui Q, et al. Weak ionization induced interfacial deposition and transformation towards fast-charging $\mathrm{NaTi}_{2}\left(\mathrm{PO}_{4}\right)_{3}$ nanowire bundles for advanced aqueous sodium-ion capacitors. Adv Funct Mater, 2021, 31: 2101027

76 Kareis CM, Lapidus SH, Her JH, et al. Non-Prussian blue structures and magnetic ordering of $\mathrm{Na}_{2} \mathrm{Mn}^{\mathrm{II}}\left[\mathrm{Mn}^{\mathrm{II}}(\mathrm{CN})_{6}\right]$ and $\mathrm{Na}_{2} \mathrm{Mn}^{\mathrm{II}}\left[\mathrm{Mn}^{\mathrm{II}}\right.$ $\left.(\mathrm{CN})_{6}\right] \cdot 2 \mathrm{H}_{2} \mathrm{O}$. J Am Chem Soc, 2012, 134: 2246-2254

77 Kong B, Tang J, Wu Z, et al. Ultralight mesoporous magnetic frameworks by interfacial assembly of Prussian blue nanocubes. Angew Chem Int Ed, 2014, 53: 2888-2892

78 Su D, McDonagh A, Qiao SZ, et al. High-capacity aqueous potassiumion batteries for large-scale energy storage. Adv Mater, 2017, 29: 1604007

79 Li B, Gu P, Feng Y, et al. Ultrathin nickel-cobalt phosphate 2D nanosheets for electrochemical energy storage under aqueous/solid-state electrolyte. Adv Funct Mater, 2017, 27: 1605784

$80 \mathrm{Xu}$ J, Xiao T, Tan $\mathrm{X}$, et al. A new asymmetric aqueous supercapacitor: $\mathrm{Co}_{3} \mathrm{O}_{4} / / \mathrm{Co}_{3} \mathrm{O}_{4} @$ polypyrrole. J Alloys Compd, 2017, 706: 351-357

81 Zhu J, Song D, Pu T, et al. Two-dimensional porous $\mathrm{ZnCo}_{2} \mathrm{O}_{4}$ thin sheets assembled by $3 \mathrm{D}$ nanoflake array with enhanced performance for aqueous asymmetric supercapacitor. Chem Eng J, 2018, 336: 679689

82 Wang X, Liu B, Liu R, et al. Fiber-based flexible all-solid-state asymmetric supercapacitors for integrated photodetecting system. Angew Chem, 2014, 126: 1880-1884

83 Ghosh D, Das CK. Hydrothermal growth of hierarchical $\mathrm{Ni}_{3} \mathrm{~S}_{2}$ and $\mathrm{Co}_{3} \mathrm{~S}_{4}$ on a reduced graphene oxide hydrogel@Ni foam: A highenergy-density aqueous asymmetric supercapacitor. ACS Appl Mater Interfaces, 2015, 7: 1122-1131

84 Yang J, Yu C, Fan X, et al. Electroactive edge site-enriched nickelcobalt sulfide into graphene frameworks for high-performance asymmetric supercapacitors. Energy Environ Sci, 2016, 9: 1299-1307

85 Liu W, Liu W, Jiang Y, et al. Binder-free electrodes for advanced potassium-ion batteries: A review. Chin Chem Lett, 2021, 32: 12991308

86 Li L, Liu W, Dong H, et al. Surface and interface engineering of nanoarrays toward advanced electrodes and electrochemical energy storage devices. Adv Mater, 2021, 33: 2004959

87 Li R, Lin Z, Ba X, et al. Integrated copper-nickel oxide mesoporous nanowire arrays for high energy density aqueous asymmetric supercapacitors. Nanoscale Horiz, 2016, 1: 150-155

88 Ye L, Zhao L, Zhang $\mathrm{H}$, et al. Serpent-cactus-like Co-doped $\mathrm{Ni}(\mathrm{OH})_{2} /$ $\mathrm{Ni}_{3} \mathrm{~S}_{2}$ hierarchical structure composed of ultrathin nanosheets for use in efficient asymmetric supercapacitors. J Mater Chem A, 2017, 5: 1603-1613

89 Ding R, Li X, Shi W, et al. One-pot solvothermal synthesis of ternary $\mathrm{Ni}$-Co-P micro/nano-structured materials for high performance aqueous asymmetric supercapacitors. Chem Eng J, 2017, 320: 376-388

90 Zhai $\mathrm{T}, \mathrm{Lu} \mathrm{X}$, Ling $\mathrm{Y}$, et al. A new benchmark capacitance for supercapacitor anodes by mixed-valence sulfur-doped $\mathrm{V}_{6} \mathrm{O}_{13-x}$. $\mathrm{Adv}$
Mater, 2014, 26: 5869-5875

91 Zhai T, Wan L, Sun S, et al. Phosphate ion functionalized $\mathrm{Co}_{3} \mathrm{O}_{4}$ ultrathin nanosheets with greatly improved surface reactivity for high performance pseudocapacitors. Adv Mater, 2017, 29: 1604167

92 Lu Z, Wu X, Jiang M, et al. Transition metal oxides/hydroxides nanoarrays for aqueous electrochemical energy storage systems. Sci China Mater, 2014, 57: 59-69

93 Zhang K, Wei Y, Huang J, et al. A generalized one-step in situ formation of metal sulfide/reduced graphene oxide nanosheets toward high-performance supercapacitors. Sci China Mater, 2020, 63: 18981909

94 Wang X, Tian L, Long X, et al. Cracked bark-inspired ternary metallic sulfide $\left(\mathrm{NiCoMnS}_{4}\right)$ nanostructure on carbon cloth for high-performance aqueous asymmetric supercapacitors. Sci China Mater, 2021, 64: 1632-1641

95 Lei X, Ge S, Yang TY, et al. Ni-Mo-S@Ni-P composite materials as binder-free electrodes for aqueous asymmetric supercapacitors with enhanced performance. J Power Sources, 2020, 477: 229022

96 Song Z, Zhou $\mathrm{H}$. Towards sustainable and versatile energy storage devices: An overview of organic electrode materials. Energy Environ Sci, 2013, 6: 2280-2301

97 Huang J, Dong X, Guo Z, et al. Progress of organic electrodes in aqueous electrolyte for energy storage and conversion. Angew Chem Int Ed, 2020, 59: 18322-18333

98 Liang Y, Tao Z, Chen J. Organic electrode materials for rechargeable lithium batteries. Adv Energy Mater, 2012, 2: 742-769

99 Liang Y, Jing Y, Gheytani S, et al. Universal quinone electrodes for long cycle life aqueous rechargeable batteries. Nat Mater, 2017, 16 841-848

100 Mulder FM, Weninger BMH, Middelkoop J, et al. Efficient electricity storage with a battolyser, an integrated Ni-Fe battery and electrolyser. Energy Environ Sci, 2017, 10: 756-764

101 Xia H, Hong C, Li B, et al. Facile synthesis of hematite quantum-dot/ functionalized graphene-sheet composites as advanced anode materials for asymmetric supercapacitors. Adv Funct Mater, 2015, 25: 627635

102 Lin TW, Dai CS, Hung KC. High energy density asymmetric supercapacitor based on $\mathrm{NiOOH} / \mathrm{Ni}_{3} \mathrm{~S}_{2} / 3 \mathrm{D}$ graphene and $\mathrm{Fe}_{3} \mathrm{O}_{4} /$ graphene composite electrodes. Sci Rep, 2015, 4: 7274

103 Wang $\mathrm{H}, \mathrm{Xu} \mathrm{Z}$, Yi H, et al. One-step preparation of single-crystalline $\mathrm{Fe}_{2} \mathrm{O}_{3}$ particles/graphene composite hydrogels as high performance anode materials for supercapacitors. Nano Energy, 2014, 7: 86-96

104 Jiang Y, Zhao D, Ba D, et al. "Carbon-glue" enabled highly stable and high-rate $\mathrm{Fe}_{3} \mathrm{O}_{4}$ nanorod anode for flexible quasi-solid-state nickelcopper//iron alkaline battery. Adv Mater Interfaces, 2018, 5: 1801043

105 Li R, Wang Y, Zhou C, et al. Carbon-stabilized high-capacity ferroferric oxide nanorod array for flexible solid-state alkaline battery-supercapacitor hybrid device with high environmental suitability. Adv Funct Mater, 2015, 25: 5384-5394

106 Li R, Ba X, Zhang $\mathrm{H}$, et al. Conformal multifunctional titania shell on iron oxide nanorod conversion electrode enables high stability exceeding 30000 cycles in aqueous electrolyte. Adv Funct Mater, 2018, 28: 1800497

107 Zhao Z, Ye Y, Zhu W, et al. Bismuth oxide nanoflake@carbon film: A free-standing battery-type electrode for aqueous sodium ion hybrid supercapacitors. Chin Chem Lett, 2018, 29: 629-632

108 Zuo W, Zhu W, Zhao D, et al. Bismuth oxide: A versatile highcapacity electrode material for rechargeable aqueous metal-ion batteries. Energy Environ Sci, 2016, 9: 2881-2891

109 Zheng H, Li H, Yu M, et al. Vertical bismuth oxide nanosheets with enhanced crystallinity: Promising stable anodes for rechargeable alkaline batteries. J Mater Chem A, 2017, 5: 25539-25544

$110 \mathrm{Yu}$ N, Gao L, Zhao S, et al. Electrodeposited $\mathrm{PbO}_{2}$ thin film as positive electrode in $\mathrm{PbO}_{2} / \mathrm{AC}$ hybrid capacitor. Electrochim Acta, 2009, 54: 3835-3841

$111 \mathrm{Yu} \mathrm{N}$, Gao L. Electrodeposited $\mathrm{PbO}_{2}$ thin film on Ti electrode for application in hybrid supercapacitor. Electrochem Commun, 2009, 11: $220-222$ 
112 Perret $\mathrm{P}$, Khani $\mathrm{Z}$, Brousse $\mathrm{T}$, et al. Carbon $/ \mathrm{PbO}_{2}$ asymmetric electrochemical capacitor based on methanesulfonic acid electrolyte. Electrochim Acta, 2011, 56: 8122-8128

113 Soumya MS, Binitha G, Praveen P, et al. Electrochemical performance of $\mathrm{PbO}_{2}$ and $\mathrm{PbO}_{2}-\mathrm{CNT}$ composite electrodes for energy storage devices. J Nanosci Nanotechnol, 2015, 15: 703-708

114 Kopczyński K, Kolanowski Ł, Baraniak M, et al. Highly amorphous $\mathrm{PbO}_{2}$ as an electrode in hybrid electrochemical capacitors. Curr Appl Phys, 2017, 17: 66-71

115 Bao J, Lin N, Guo J, et al. Effects of nano- $\mathrm{SiO}_{2}$ doped $\mathrm{PbO}_{2}$ as the positive electrode on the performance of lead-carbon hybrid capacitor. J Colloid Interface Sci, 2020, 574: 377-384

116 Zhang $\mathrm{W}$, Lin $\mathrm{H}$, Kong $\mathrm{H}$, et al. High energy density $\mathrm{PbO}_{2} /$ activated carbon asymmetric electrochemical capacitor based on lead dioxide electrode with three-dimensional porous titanium substrate. Int J Hydrogen Energy, 2014, 39: 17153-17161

117 Chmiola J, Yushin G, Gogotsi Y, et al. Anomalous increase in carbon capacitance at pore sizes less than 1 nanometer. Science, 2006, 313: $1760-1763$

118 Fleischmann S, Mitchell JB, Wang R, et al. Pseudocapacitance: From fundamental understanding to high power energy storage materials. Chem Rev, 2020, 120: 6738-6782

119 Jeżowski P, Crosnier O, Deunf E, et al. Safe and recyclable lithium-ion capacitors using sacrificial organic lithium salt. Nat Mater, 2018, 17: $167-173$

$120 \mathrm{Lu}$ WJ, Huang SZ, Miao L, et al. Synthesis of $\mathrm{MnO}_{2} / \mathrm{N}$-doped ultramicroporous carbon nanospheres for high-performance supercapacitor electrodes. Chin Chem Lett, 2017, 28: 1324-1329

121 Tomko T, Rajagopalan R, Aksoy P, et al. Synthesis of boron/nitrogen substituted carbons for aqueous asymmetric capacitors. Electrochim Acta, 2011, 56: 5369-5375

122 Zhou L, Cao H, Zhu S, et al. Hierarchical micro-/mesoporous N- and O-enriched carbon derived from disposable cashmere: A competitive cost-effective material for high-performance electrochemical capacitors. Green Chem, 2015, 17: 2373-2382

$123 \mathrm{Ma} \mathrm{H}$, Kong $\mathrm{D}, \mathrm{Xu} \mathrm{Y}$, et al. Disassembly-reassembly approach to $\mathrm{RuO}_{2}$ /graphene composites for ultrahigh volumetric capacitance supercapacitor. Small, 2017, 13: 1701026

124 Tang W, Hou YY, Wang XJ, et al. A hybrid of $\mathrm{MnO}_{2}$ nanowires and MWCNTs as cathode of excellent rate capability for supercapacitors. J Power Sources, 2012, 197: 330-333

$125 \mathrm{Qu} \mathrm{Q}, \mathrm{Zhu} \mathrm{Y}$, Gao X, et al. Core-shell structure of polypyrrole grown on $\mathrm{V}_{2} \mathrm{O}_{5}$ nanoribbon as high performance anode material for supercapacitors. Adv Energy Mater, 2012, 2: 950-955

126 Yu M, Zhao S, Feng H, et al. Engineering thin $\mathrm{MoS}_{2}$ nanosheets on TiN nanorods: Advanced electrochemical capacitor electrode and hydrogen evolution electrocatalyst. ACS Energy Lett, 2017, 2: 18621868

127 Gui Q, Wu L, Li Y, et al. Scalable wire-type asymmetric pseudocapacitor achieving high volumetric energy/power densities and ultralong cycling stability of 100000 times. Adv Sci, 2019, 6: 1802067

128 Zeng Y, Han Y, Zhao Y, et al. Advanced Ti-doped $\mathrm{Fe}_{2} \mathrm{O}_{3} @ P E D O T$ core/shell anode for high-energy asymmetric supercapacitors. Adv Energy Mater, 2015, 5: 1402176

129 Ghosh K, Yue CY, Sk MM, et al. Development of 3D urchin-shaped coaxial manganese dioxide@polyaniline $\left(\mathrm{MnO}_{2} @ \mathrm{PANI}\right)$ composite and self-assembled 3D pillared graphene foam for asymmetric allsolid-state flexible supercapacitor application. ACS Appl Mater Interfaces, 2017, 9: 15350-15363

130 Zhang SW, Yin BS, Liu C, et al. Self-assembling hierarchical $\mathrm{NiCo}_{2} \mathrm{O}_{4} /$ $\mathrm{MnO}_{2}$ nanosheets and $\mathrm{MoO}_{3} / \mathrm{PPy}$ core-shell heterostructured nanobelts for supercapacitor. Chem Eng J, 2017, 312: 296-305

131 Wang SQ, Cai X, Song Y, et al. $\mathrm{VO}_{x} @ \mathrm{MoO}_{3}$ nanorod composite for high-performance supercapacitors. Adv Funct Mater, 2018, 28: 1803901

132 Saeed G, Kumar S, Kim NH, et al. Fabrication of 3D graphene-CNTs/ a- $-\mathrm{MoO}_{3}$ hybrid film as an advance electrode material for asymmetric supercapacitor with excellent energy density and cycling life. Chem
Eng J, 2018, 352: 268-276

133 Melchior SA, Raju K, Ike IS, et al. High-voltage symmetric supercapacitor based on $2 \mathrm{D}$ titanium carbide (MXene, $\mathrm{Ti}_{2} \mathrm{CT}_{x}$ )/carbon nanosphere composites in a neutral aqueous electrolyte. J Electrochem Soc, 2018, 165: A501-A511

134 Mendoza-Sánchez B, Gogotsi Y. Synthesis of two-dimensional materials for capacitive energy storage. Adv Mater, 2016, 28: 6104-6135

135 Wang Y, Dou H, Wang J, et al. Three-dimensional porous MXene/ layered double hydroxide composite for high performance supercapacitors. J Power Sources, 2016, 327: 221-228

136 Naguib M, Mochalin VN, Barsoum MW, et al. 25th anniversary article: MXenes: A new family of two-dimensional materials. Adv Mater, 2014, 26: 992-1005

137 Lukatskaya MR, Mashtalir O, Ren CE, et al. Cation intercalation and high volumetric capacitance of two-dimensional titanium carbide. Science, 2013, 341: 1502-1505

138 Wang $\mathrm{C}$, Chen $\mathrm{S}$, Xie $\mathrm{H}$, et al. Atomic $\mathrm{Sn}^{4+}$ decorated into vanadium carbide MXene interlayers for superior lithium storage. Adv Energy Mater, 2019, 9: 1802977

139 Luo J, Zhang W, Yuan H, et al. Pillared structure design of MXene with ultralarge interlayer spacing for high-performance lithium-ion capacitors. ACS Nano, 2017, 11: 2459-2469

140 Li J, Yuan X, Lin C, et al. Achieving high pseudocapacitance of 2D titanium carbide (MXene) by cation intercalation and surface modification. Adv Energy Mater, 2017, 7: 1602725

141 Dong X, Zhang Y, Ding B, et al. Layer-by-layer self-assembled twodimensional MXene/layered double hydroxide composites as cathode for alkaline hybrid batteries. J Power Sources, 2018, 390: 208-214

142 Wang J, Tang J, Ding B, et al. Hierarchical porous carbons with layerby-layer motif architectures from confined soft-template self-assembly in layered materials. Nat Commun, 2017, 8: 15717-15725

143 Jiang Y, Liu J. Definitions of pseudocapacitive materials: A brief review. Energy Environ Mater, 2019, 2: 30-37

144 Zhang X, Zhang Z, Zhou Z. MXene-based materials for electrochemical energy storage. J Energy Chem, 2018, 27: 73-85

145 Zhu K, Zhang H, Ye K, et al. Two-dimensional titanium carbide MXene as a capacitor-type electrode for rechargeable aqueous Li-ion and Na-ion capacitor batteries. ChemElectroChem, 2017, 4: 30183025

146 James SL. Metal-organic frameworks. Chem Soc Rev, 2003, 32: 276

147 Dou Y, Grande C, Kaiser A, et al. Highly structured metal-organic framework nanofibers for methane storage. Sci China Mater, 2021, 64: $1742-1750$

148 Furukawa H, Cordova KE, O'Keeffe M, et al. The chemistry and applications of metal-organic frameworks. Science, 2013, 341: 1230444

149 Sheberla D, Bachman JC, Elias JS, et al. Conductive MOF electrodes for stable supercapacitors with high areal capacitance. Nat Mater, 2017, 16: 220-224

150 Zhou W, Lv S, Liu X, et al. A directly grown pristine Cu-CAT metalorganic framework as an anode material for high-energy sodium-ion capacitors. Chem Commun, 2019, 55: 11207-11210

$151 \mathrm{Wu} \mathrm{K}$, Huang J, Yi J, et al. Recent advances in polymer electrolytes for zinc ion batteries: Mechanisms, properties, and perspectives. Adv Energy Mater, 2020, 10: 1903977

152 Zhu W, Li R, Xu P, et al. Vanadium trioxide@carbon nanosheet arraybased ultrathin flexible symmetric hydrogel supercapacitors with $2 \mathrm{~V}$ voltage and high volumetric energy density. J Mater Chem A, 2017, 5 : 22216-22223

153 Huang Y, Li Z, Pei Z, et al. Solid-state rechargeable Zn//NiCo and Znair batteries with ultralong lifetime and high capacity: The role of a sodium polyacrylate hydrogel electrolyte. Adv Energy Mater, 2018, 8: 1802288

154 Zhu M, Wang X, Tang $\mathrm{H}$, et al. Antifreezing hydrogel with high zinc reversibility for flexible and durable aqueous batteries by cooperative hydrated cations. Adv Funct Mater, 2020, 30: 1907218

155 Shen Y, Liu B, Liu X, et al. Water-in-salt electrolyte for safe and highenergy aqueous battery. Energy Storage Mater, 2021, 34: 461-474

156 Liang T, Hou R, Dou Q, et al. The applications of water-in-salt 
electrolytes in electrochemical energy storage devices. Adv Funct Mater, 2021, 31: 2006749

157 Suo L, Borodin O, Gao T, et al. "Water-in-salt" electrolyte enables high-voltage aqueous lithium-ion chemistries. Science, 2015, 350: 938943

158 Suo L, Oh D, Lin Y, et al. How solid-electrolyte interphase forms in aqueous electrolytes. J Am Chem Soc, 2017, 139: 18670-18680

159 Zhang Y, Nie P, Xu C, et al. High energy aqueous sodium-ion capacitor enabled by polyimide electrode and high-concentrated electrolyte. Electrochim Acta, 2018, 268: 512-519

160 Lee MH, Kim SJ, Chang D, et al. Toward a low-cost high-voltage sodium aqueous rechargeable battery. Mater Today, 2019, 29: 26-36

161 Dou Q, Wang Y, Wang A, et al. "Water in salt/ionic liquid" electrolyte for $2.8 \mathrm{~V}$ aqueous lithium-ion capacitor. Sci Bull, 2020, 65: 1812-1822

162 Wang F, Borodin O, Ding MS, et al. Hybrid aqueous/non-aqueous electrolyte for safe and high-energy Li-ion batteries. Joule, 2018, 2: 927-937

163 Yamada Y, Usui K, Sodeyama K, et al. Hydrate-melt electrolytes for high-energy-density aqueous batteries. Nat Energy, 2016, 1: 1-9

164 Jiang L, Liu L, Yue J, et al. High-voltage aqueous Na-ion battery enabled by inert-cation-assisted water-in-salt electrolyte. Adv Mater, 2020, 32: 1904427

165 Deng W, Wang X, Liu C, et al. Li/K mixed superconcentrated aqueous electrolyte enables high-performance hybrid aqueous supercapacitors. Energy Storage Mater, 2019, 20: 373-379

166 Li Y, Tang F, Wang R, et al. Novel dual-ion hybrid supercapacitor based on a $\mathrm{NiCo}_{2} \mathrm{O}_{4}$ nanowire cathode and $\mathrm{MoO}_{2}-\mathrm{C}$ nanofilm anode. ACS Appl Mater Interfaces, 2016, 8: 30232-30238

167 Jiang Y, Zhou C, Liu J. A non-polarity flexible asymmetric supercapacitor with nickel nanoparticle@carbon nanotube three-dimensional network electrodes. Energy Storage Mater, 2018, 11: 75-82

168 Chao D, Zhou W, Xie F, et al. Roadmap for advanced aqueous batteries: From design of materials to applications. Sci Adv, 2020, 6: eaba4098

169 Ma X, Cheng J, Dong L, et al. Multivalent ion storage towards highperformance aqueous zinc-ion hybrid supercapacitors. Energy Storage Mater, 2019, 20: 335-342

170 Li Y, Lu P, Shang P, et al. Pyridinic nitrogen enriched porous carbon derived from bimetal organic frameworks for high capacity zinc ion hybrid capacitors with remarkable rate capability. J Energy Chem, 2021, 56: 404-411

171 Song M, Tan H, Chao D, et al. Recent advances in Zn-ion batteries. Adv Funct Mater, 2018, 28: 1802564

172 Fang G, Zhou J, Pan A, et al. Recent advances in aqueous zinc-ion batteries. ACS Energy Lett, 2018, 3: 2480-2501

173 Wang Z, Huang J, Guo Z, et al. A metal-organic framework host for highly reversible dendrite-free zinc metal anodes. Joule, 2019, 3: 12891300

174 Xie X, Liang S, Gao J, et al. Manipulating the ion-transfer kinetics and interface stability for high-performance zinc metal anodes. Energy Environ Sci, 2020, 13: 503-510

175 Liu J, Zhang Y, Zhang L, et al. Graphitic carbon nitride $\left(\mathrm{g}-\mathrm{C}_{3} \mathrm{~N}_{4}\right)-$ derived $\mathrm{N}$-rich graphene with tuneable interlayer distance as a highrate anode for sodium-ion batteries. Adv Mater, 2019, 31: 1901261

176 Browne MP, Sofer Z, Pumera M. Layered and two dimensional metal oxides for electrochemical energy conversion. Energy Environ Sci, 2019, 12: 41-58

177 Chodankar NR, Dubal DP, Ji SH, et al. Self-assembled nickel pyrophosphate-decorated amorphous bimetal hydroxides 2D-on-2D nanostructure for high-energy solid-state asymmetric supercapacitor. Small, 2019, 15: 1901145

178 Yao L, Wu Q, Zhang P, et al. Scalable 2D hierarchical porous carbon nanosheets for flexible supercapacitors with ultrahigh energy density. Adv Mater, 2018, 30: 1706054

179 Wang C, Pei Z, Meng Q, et al. Toward flexible zinc-ion hybrid capacitors with superhigh energy density and ultralong cycling life: The pivotal role of $\mathrm{ZnCl}_{2}$ salt-based electrolytes. Angew Chem Int Ed, 2021, 60: 990-997
180 Huang Z, Chen A, Mo F, et al. Phosphorene as cathode material for high-voltage, anti-self-discharge zinc ion hybrid capacitors. Adv Energy Mater, 2020, 10: 2001024

181 Li Y, Fu J, Zhong C, et al. Recent advances in flexible zinc-based rechargeable batteries. Adv Energy Mater, 2019, 9: 1802605

182 Dong L, Ma X, Li Y, et al. Extremely safe, high-rate and ultralong-life zinc-ion hybrid supercapacitors. Energy Storage Mater, 2018, 13: 96 102

183 Dong L, Yang W, Yang W, et al. Multivalent metal ion hybrid capacitors: A review with a focus on zinc-ion hybrid capacitors. J Mater Chem A, 2019, 7: 13810-13832

Acknowledgements This work was supported by the National Natural Science Foundation of China (51972257, 52072136 and 51872104), the National Key R\&D Program of China (2016YFA0202602) and the Natural Science Foundation of Hubei Province (2018CFB581).

Author contributions Gui Q and Ba D wrote the manuscript; Li L and Liu $\mathrm{W}$ prepared the figures; Liu J and Li Y provided the overall concept and revised the manuscript. All authors contributed to the general discussion.

Conflict of interest The authors declare that they have no conflict of interest.

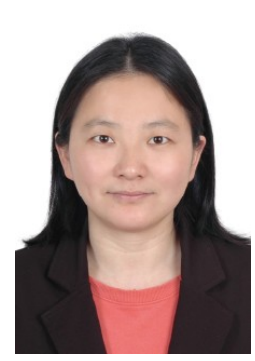

Yuanyuan $\mathbf{L i}$ received her $\mathrm{MSc}$ and $\mathrm{PhD}$ degrees from the Central China Normal University (CCNU) in 2004 and 2009, respectively. She has been a faculty at the School of Optical and Electronic Information, Huazhong University of Science and Technology, China since April, 2010 and is now an associate professor. She worked as a visiting scientist at the University of Wollongong, Australia in 2018. Her research interests include the synthesis of advanced nanostructures and their applications in electrochemical energy storage.

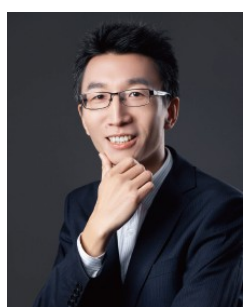

Jinping Liu received his $\mathrm{PhD}$ degree from CCNU in June 2009. During the period of 2008-2011, he did visiting and post-doctoral research at Nanyang Technological University (NTU) in Singapore. He is currently chair professor at Wuhan University of Technology. The research interests in Dr. Liu's group include the nanostructures syntheses and their electrochemical applications (batteries, supercapacitors \& electrocatalysis).

\section{水系混合超级电容器先进电极材料与器件研究进展}

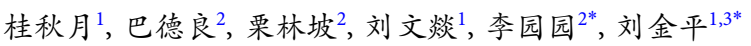

摘要 使用有毒、易燃有机电解液的传统电化学储能器件存在较大的 安全隐患. 相比之下, 新型水系混合超级电容器(AHSCs)具有更高的安 全性和环境友好性. AHSCs作为水系电池和水系超级电容器之间的桥 梁, 能够结合电池电极高的比容量和电容电极大功率和长寿命的优点, 有望与电池系统结合使用或者完全替代电池系统. 在过去的几十年中, 研究者致力于开发先进的电极材料和设计结构新颖的水系混合电容 器. 然而, 全电池搭配时电池型电极和电容型电极存在容量和动力学不 匹配的问题. 本文从电池电极、电容电极和新型电解质的概念设计三 个方面综述了AHSCs的研究进展, 讨论了具有“双离子”储能机制和非 极性特性的多功能AHSCs, 并进一步阐述了多价AHSCs（特别是锌离 子AHSCs)的最新进展及有待解决的关键问题. 最后, 本文总结了 AHSCs面临的挑战, 并对未来构筑更高功率密度和多功能AHSCs器件 的发展方向作出了展望. 